\title{
Review of the November 11, 1905 Earthquake: Seismic Intensity Data, Magnitude, and Location Report
}

María-José Jiménez

February 2021

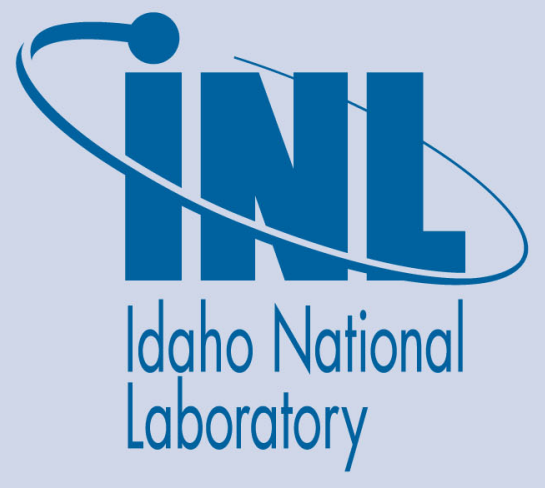

The INL is a U.S. Department of Energy National Laboratory operated by Battelle Energy Alliance 


\section{DISCLAIMER}

This information was prepared as an account of work sponsored by an agency of the U.S. Government. Neither the U.S. Government nor any agency thereof, nor any of their employees, makes any warranty, expressed or implied, or assumes any legal liability or responsibility for the accuracy, completeness, or usefulness, of any information, apparatus, product, or process disclosed, or represents that its use would not infringe privately owned rights. References herein to any specific commercial product, process, or service by trade name, trade mark, manufacturer, or otherwise, does not necessarily constitute or imply its endorsement, recommendation, or favoring by the U.S. Government or any agency thereof. The views and opinions of authors expressed herein do not necessarily state or reflect those of the U.S. Government or any agency thereof. 


\title{
Review of the November 11, 1905 Earthquake: Seismic Intensity Data, Magnitude, and Location Report
}

\author{
María-José Jiménez \\ Spanish National Research Council \\ Madrid, Spain
}

February 2021

Idaho National Laboratory Idaho Falls, Idaho 83415

http://www.inl.gov

Prepared for the

U.S. Department of Energy

Office of Nuclear Energy

Under DOE Idaho Operations Office

Contract DE-AC07-05ID14517 



\section{SUMMARY}

The macroseismic location and magnitude of the Shoshone 1905 earthquake has been based on the application of objective and quantitative approaches that produce estimates of earthquake source location and magnitude, and associated uncertainties. The performance of all three approaches applied depends critically on the characteristics of the seismic intensity field. Regional intensity attenuation relations were derived based on a calibration set of earthquakes and then, the procedure was validated using three independent very recent events. The macroseismic epicenter location was determined by either a grid search procedure, the spatial distribution of the sites experiencing the largest intensities, or a combination of both. The macroseismic magnitude estimates are based on the derived regional intensity attenuation relations. There is consistency in the location and magnitude of the November 1905 earthquake as obtained by the three methods. The overlapping region of the $68 \%$ bootstrap resampling solutions suggests a reliable epicenter location within $41.550 \mathrm{~N}$ $-42.060 \mathrm{~N}$ and $113.478 \mathrm{~W}-112.320 \mathrm{~W}$. This region encloses the original Oaks (1992) epicenter location. Macroseismic magnitude estimates range between 5.87 and 6.05 . 



\title{
Review of the November 11, 1905 Earthquake: Seismic Intensity Data, Magnitude, and Location
}

\author{
María-José Jiménez \\ Department of Geology \\ MNCN-CSIC (Spanish National Research Council) \\ Madrid, Spain
}



Table of Contents

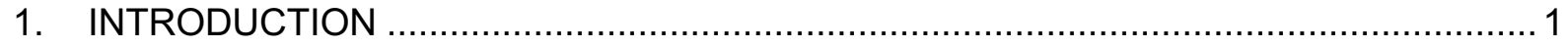

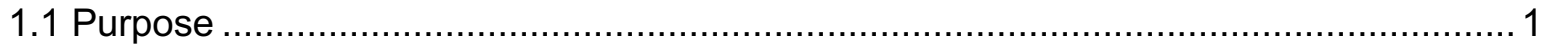

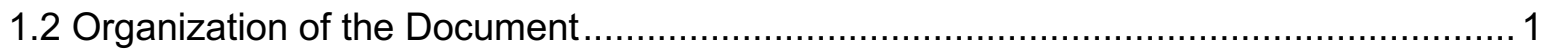

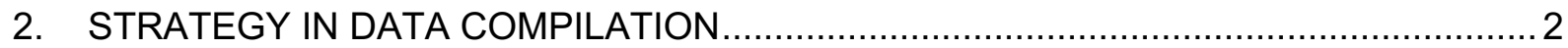

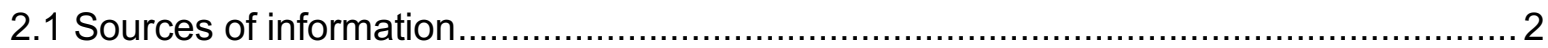

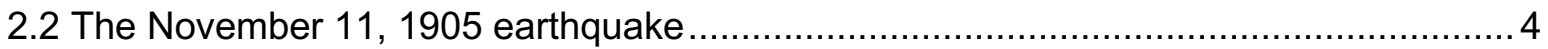

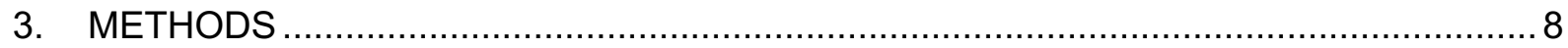

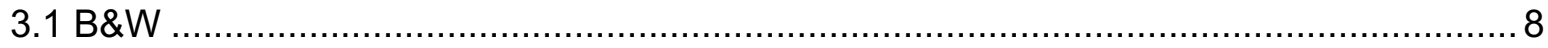

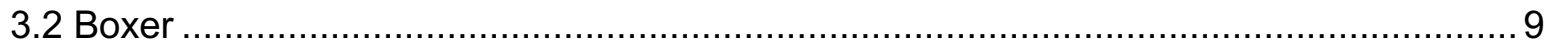

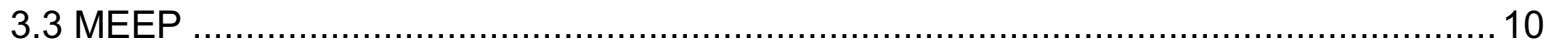

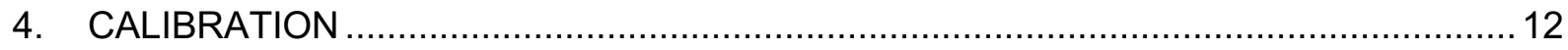

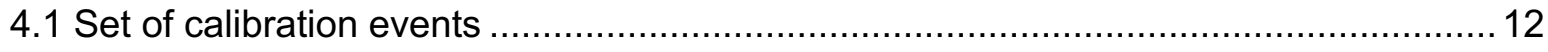

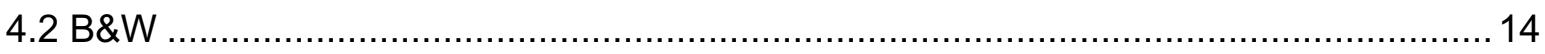

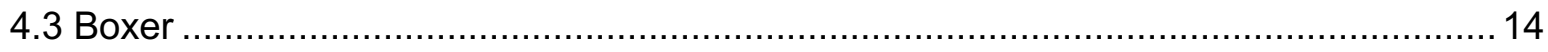

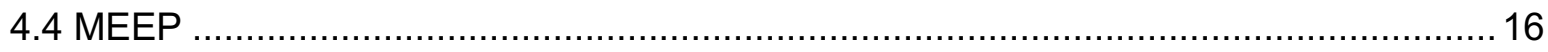

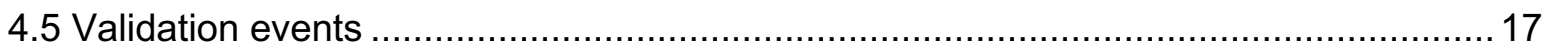

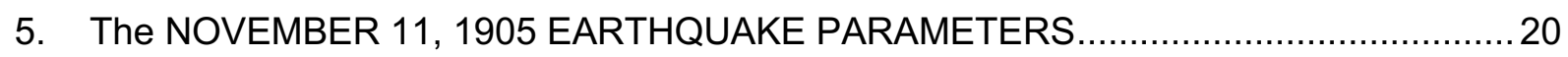

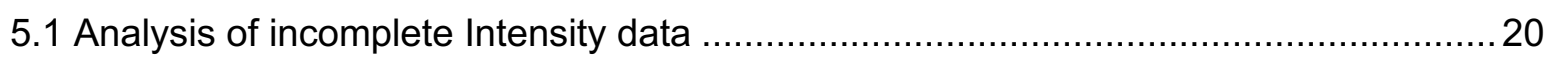

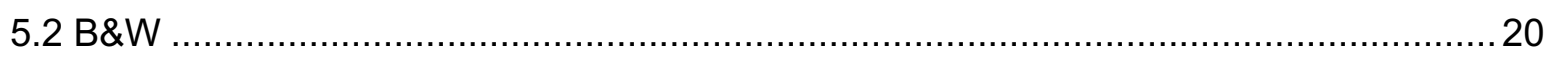

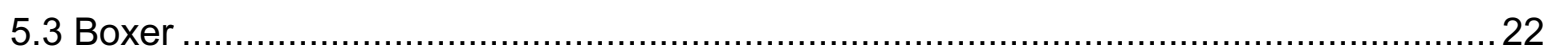

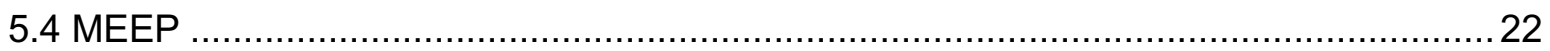

5.5 Macroseismic location and magnitude of the November 11, 1905 earthquake ............23

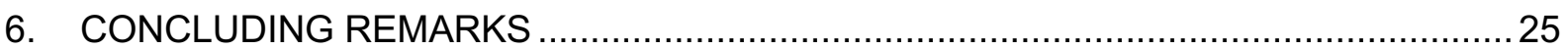

REFERENCES

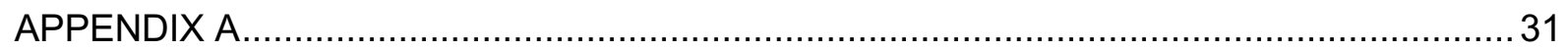

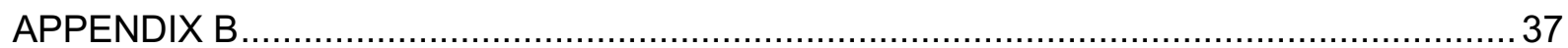





\section{INTRODUCTION}

\subsection{Purpose}

This document is a report summarizing the data and information, the methodologies employed, and the results of the analysis to calculate the magnitude and location for the November 11, 1905 earthquake using modern approaches as defined in the technical specifications in $\mathrm{CCl}$ Contract number 205676-03. Investigation into the location and size of the November 11, 1905 earthquake is needed for characterizing earthquake source models to be used in the INL Sitewide SSHAC Level 3 probabilistic seismic hazard analysis (PSHA).

According to the technical specifications, the review of the November 11, 1905 earthquake should be based on applying objective and quantitative approaches to analyze individual seismic intensity assignments (based on the assessment of macroseismic effects) that produce estimates of earthquake source location and magnitude, and associated uncertainties. These approaches developed in recent years are the following: B\&W (Bakun and Wentworth,1997), Boxer (Gasperini et al.,1999, 2010), MEEP (Musson and Jimenez, 2008; Musson, 2009).

\subsection{Organization of the Document}

Following this introduction describing the purpose of the document, Section 2 summarizes the strategy in compiling the data with a description of the different sources of historical and instrumental information. The criteria for the selection of earthquakes for the investigation are given together with references to the main sources describing the damage and effects of the November 11, 1905 earthquake. It includes a critical review of the intensity assignments and macroseismic data.

Section 3 introduces the background of the B\&W (Bakun and Wentworth,1997), Boxer (Gasperini et al.,1999, 2010), and MEEP (Musson and Jimenez, 2008, Musson, 2009) methods for the determination of macroseismic earthquake location and magnitude giving the details on the derivation of parameters in each of the approaches.

Section 4 includes the description of the set of calibration earthquakes and calibration procedures. First, it describes the criteria applied for the selection of the calibration set. Next, it describes the calibration procedures and the resulting calibration parameters for each method. Then, the procedures are tested with a set of very recent validation events.

Section 5 incorporates the analysis of the intensity assignments of the November 11, 1905 earthquake using the different techniques. It includes the estimations of the epicentral location and macroseismic magnitude of the November 11, 1905 earthquake and the associated uncertainties.

Section 6 provides the concluding remarks shortly describing the approaches for the determination of macroseismic parameters in the three methods. It discusses the performance and results obtained for each of them in relation to the characteristics of the intensity macroseismic field. 


\section{STRATEGY IN DATA COMPILATION}

\subsection{Sources of information}

As a first step, 16 earthquakes with location, magnitude $(\geq 5.5)$ and intensity data were extracted from the INL SSHAC Level 3 project, uniform moment magnitude catalog (INL_SL3) in an area extending from longitude $117^{\circ} \mathrm{W}$ to $110^{\circ} \mathrm{W}$, and latitude $40^{\circ} \mathrm{N}$ to $45^{\circ} \mathrm{N}$, for the time period 1850-2020 (Table 1 and Fig. 1).

\begin{tabular}{cccccccc}
\hline DATE & TIME & LAT & LON & E[M] & Location & Imax & MMI $\geq$ IV \\
\hline $1884-11-10$ & $08: 50: 00$ & 42.300 & -111.400 & 5.81 & Utah & VI & 3 \\
$1909-10-06$ & $02: 50: 00$ & 41.766 & -112.666 & 5.81 & Utah & VII & 2 \\
$1934-03-12$ & $15: 05: 48$ & 41.658 & -112.795 & 6.59 & Hansel Valley, UT & VIII & 105 \\
$1944-07-12$ & $19: 30: 21$ & 44.412 & -115.063 & 6.18 & southern Idaho & VII & 75 \\
$1945-02-14$ & $03: 01: 11$ & 44.607 & -115.087 & 6.03 & southern Idaho & VI & 52 \\
$1947-11-23$ & $09: 46: 05$ & 44.820 & -111.713 & 6.09 & western Montana & VIII & 218 \\
$1959-08-18$ & $06: 37: 15$ & 44.830 & -111.000 & 7.23 & Hebgen Lake, MT & X & 624 \\
$1962-08-30$ & $13: 35: 24$ & 42.035 & -111.741 & 5.72 & Cache Valley, UT & VII & 222 \\
$1975-03-28$ & $02: 31: 06$ & 42.063 & -112.525 & 6.01 & Pocatello, ID & VIII & 143 \\
$1975-06-30$ & $18: 54: 12$ & 44.688 & -110.604 & 5.83 & Yellowstone, WY & VII & 17 \\
$1983-10-28$ & $14: 06: 07$ & 43.967 & -113.899 & 6.89 & Borah Peak, ID & VII & 384 \\
$1984-08-22$ & $09: 46: 31$ & 44.377 & -114.081 & 5.55 & Devil Canyon, ID & V & 62 \\
$1994-02-03$ & $09: 05: 04$ & 42.742 & -111.134 & 5.78 & Wyoming & VII & -1 \\
$2008-02-21$ & $14: 16: 03$ & 41.144 & -114.872 & 5.97 & Wells, NV & VII & $43^{2}$ \\
$2020-03-18$ & $13: 09: 31$ & 40.751 & -112.078 & 5.57 & NNW Magna, UT & VII & $126^{2}$ \\
$2020-03-31$ & $23: 52: 31$ & 44.460 & -115.136 & 6.45 & W Challis, ID & VIII & $494^{2}$ \\
\hline 10
\end{tabular}

${ }^{1}$ only ShakeMap available; ${ }^{2}$ DYFI CDI geocoded 10km

Table 1. Magnitude $\geq 5.5$ earthquakes from the project catalog with intensity data in the area extending from $117 \mathrm{~W}$ to $110 \mathrm{~W}$, and $40 \mathrm{~N}$ to $45 \mathrm{~N}$, for the time period 1850-2020. E[M]: uniform moment magnitude estimate, Imax: Maximum intensity, MMI IV: Number of intensity data with $M M I \geq I V$.

Depths of all selected earthquakes are shallower than $20 \mathrm{~km}$ with only five events deeper than $10 \mathrm{~km}$. Magnitudes $\mathrm{E}[\mathrm{M}]$ in the catalog are uniform moment magnitude estimates calculated using NUREG-2215 procedures (USNCRC, 2012).

Modified Mercalli Intensity (MMI) data for events up to 1985 were compiled from NOAA Earthquake Intensity Database (https://www.ngdc.noaa.gov/hazard/intintro.shtml, last accessed May 2020). 
For the most recent events, the intensity data were obtained from USGS Did You Feel It? (DYFI) archives (https://earthquake.usgs.gov/data/dyfil, last accessed May 2020), with additional information for locations in Nevada for the February 21, 2008 Wells earthquake in dePolo and Pecoraro (2011)

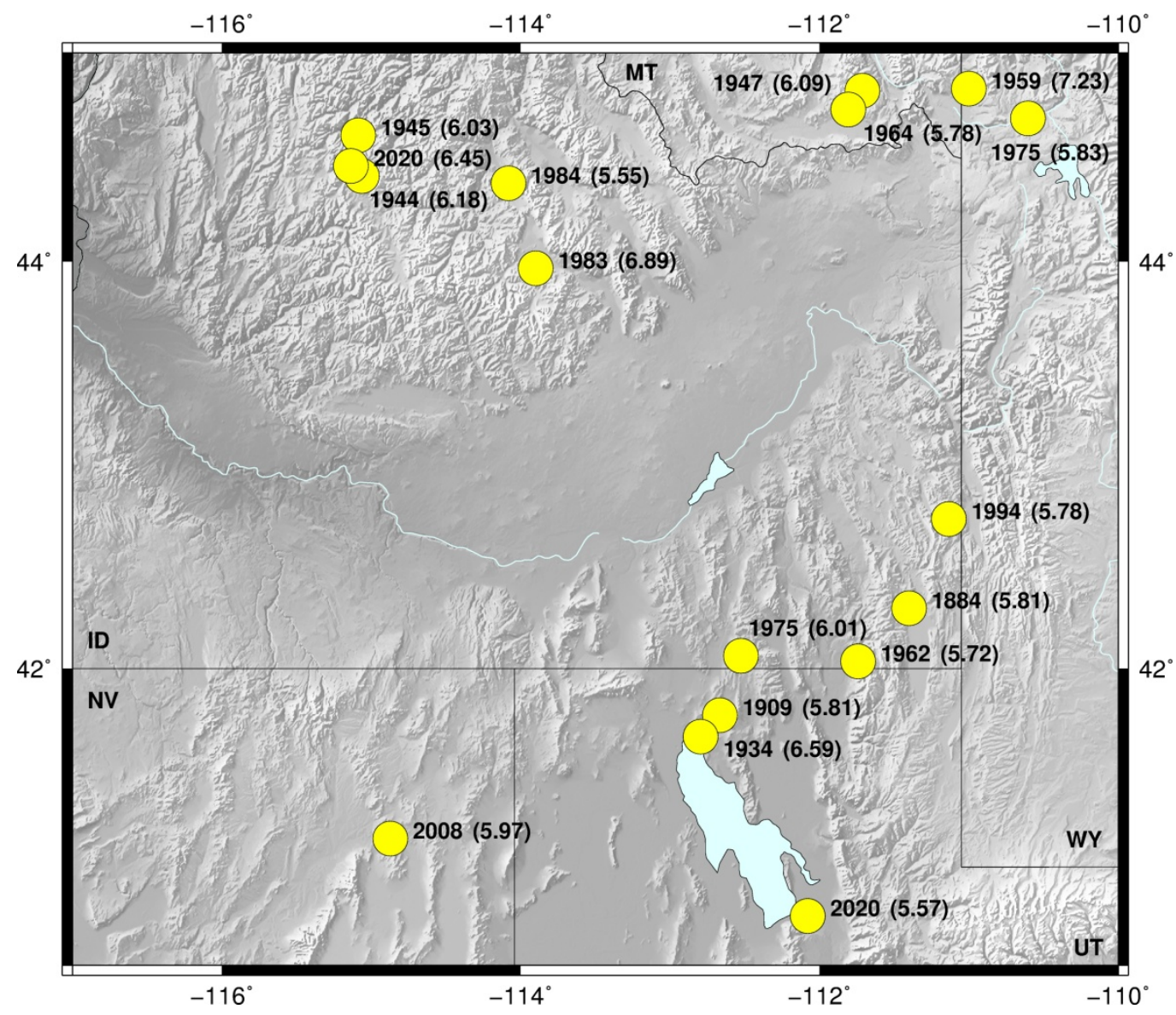

Figure 1. $E[M] \geq 5.5$ earthquakes with available intensity data extracted from the INL_SL3 project catalog in an area extending from longitude $117^{\circ} \mathrm{W}$ to $110^{\circ} \mathrm{W}$, and latitude $40^{\circ} \mathrm{N}$ to $45^{\circ} \mathrm{N}$, for the time period $1850-2020$

A compilation of papers and reports with specific data on damage and effects from significant earthquakes in the region includes:

- United States Earthquakes annual reports by: Coast and Geodetic Survey from 192868; NOAA from 1969-72; NOAA / USGS from 1973-80; and USGS from 1981-1986

- Townley and Allen (1939) Catalog of Earthquakes of the Pacific Coast of the United States 1769 to 1928

- Harpham (1991) Ms thesis on 1905, 1913 and 1916 Idaho earthquakes

- Oaks (1992) report on the 1905 earthquake

- Evans et al. (2003) paper on the 1884 Bear Lake earthquake 
- dePolo and Pecoraro (2011) report on the 2008 Wells earthquake

Additional data come from INL (Idaho National Laboratory) PSHA reports (INL, 1996, 2016), and from downloads of information available at the Idaho Geological Survey web site (https://www.idahogeology.org/ last accessed March 2020).

The sources on which NOAA data are based, like the serial publications 'United States Earthquakes' from USGS, 'Quarterly Seismological Report' and 'Monthly Weather Service Seismological Reports' from U.S. Department of Commerce, were also consulted when available.

\subsection{The November 11, 1905 earthquake}

The most comprehensive analysis on the macroseismic data of the November 11, 1905 earthquake is that in Oaks (1992). It includes a thorough investigation of primary historical documentary sources (manuscript diaries and letters, institutional records, military post records, weather observer records, and other scientific reports such as field notes) at national, subnational, state, and local archive repositories. The investigation of sources covered an area in the Western United States for an eight state region that comprised the area of the Snake River Plane and surrounding area of the Great Basin and the Basin and Range Province.

In an attempt to determine the felt area, Oaks (1992) compiled and reviewed scientific records (e.g. U.S. Department of Agriculture Weather Bureau Observers' reports, Reports of the U.S. Army Surgeons) for a wider 16-State region surrounding the Snake River Plain. Among them, very few felt reports corresponded to intensity assignments less than MMI IV, reflecting the very low population density in the Western United States at the time of the earthquake in the beginning of the $20^{\text {th }}$ century. For the same reason, only one source (Boise newspaper, The Idaho Daily Statesman, November 12, 1905) reported "not-felt" observations in six localities (Emmet, Caldwell, Payette, Mountain Home, Idaho Falls, and St Anthony). Harpham (1991) lists five more localities reported as "not felt" (Blackfoot, Montpellier, Nampa, Pocatello, and Weiser) based on newspapers accounts. As Oaks (1991) points, for some of the localities such as Pocatello which had "not-felt" reports in newspapers more reliable scientific records contained reports of the earthquake. Because of the uncertainties associated with "not-felt" observations, these have not been considered.

Based on what Oaks (1991) considered the most reliable reports on the effects and damage of the November 11, 1905 earthquake she assigned MMI values to the observations resulting in $19 \mathrm{MMl}$ assignments for cities and towns affected by the earthquake (Table 2).

Figure 2 shows the Oaks (1992) geographical distribution of all MMI intensity assignments (including uncertain "not-felt" observations). At Baker City, OR, MMI assignment is 'FELT' because of the lack of information for properly assigning a MMI value (Oaks, 1992). The information in newspapers in Idaho refers to the effects in Baker City but there are no local reports from Baker City. Only the remaining 18 sites are considered in the further application of macroseismic determination of location and magnitude parameters. 


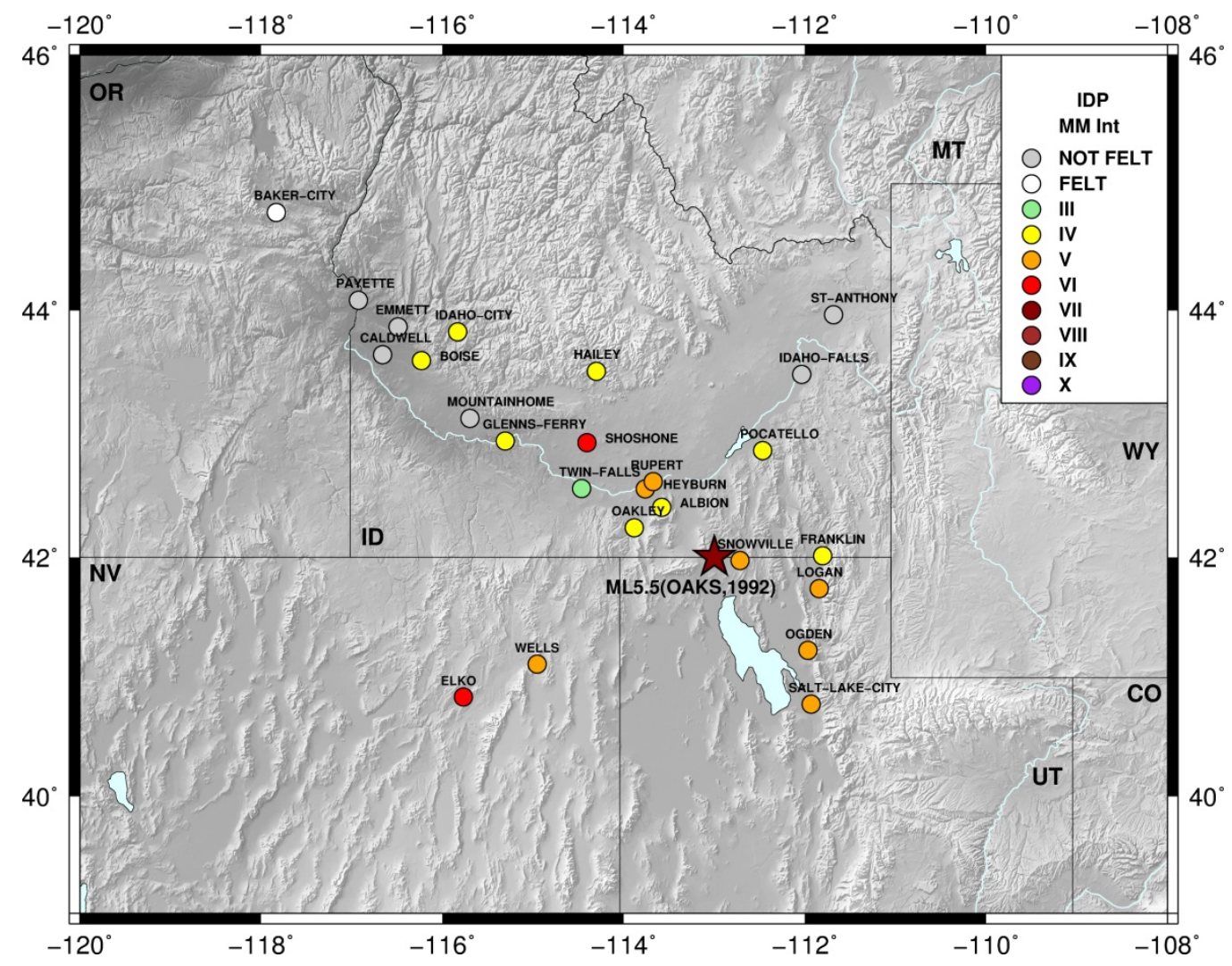

Figure 2. Colored circles are Oaks (1992) MMI assignments of the November 11, 1905 event for locations in Idaho, Utah, Nevada and Oregon. Inset: Color-coded MMI intensities. Red Star: Epicenter as determined by Oaks (1992).

A review of the available intensity data of the November 11, 1905 earthquake has been carried out using the compilation and verbatim listing of felt reports in Oaks (1992). This review suggests that MMI values assigned to Boise, ID, and Idaho City, ID, could be overestimated. According to the descriptions in the Daily Journals and Abstracts of the US Weather Bureau, and some Idaho newspapers (e.g., the Idaho Daily Statesman, the Lewiston Interstate News, and the Montpelier Examiner) an assignment of MMI of III would better correspond to the effects described. At Boise, the most detailed descriptions refer to a '... slight ...' or '... very slight earthquake shock ...', felt mainly by '... people in the top floors of the higher buildings of the city ...', and '... not noticed at all by people upon the ground or busily engaged higher up ...'. Only short reporting in some newspapers refer to a slight earthquake '... causing dishes and windows to rattle .... The text of this news is identical in all of them, suggesting that the information comes from a single source which is reproduced in the rest. The description would correspond at the most to a MMI III-IV, but closer to MMI III. For Idaho City, main news about Idaho City (the Idaho Daily Statesman) refers '... there was a slight earthquake shock ...' ' '... was too slight to do any damage ...', and '... was noticed by almost the entire population ...'. The Idaho City newspaper Idaho World just reads '... an earthquake shock was felt at this place ...' Considering that population in Idaho City in 1905 was around 300 inhabitants at the time of the earthquake (Durand 1918) and with no other information on felt effects a MMI III has been re-assigned. 


\begin{tabular}{ccccc}
\hline LAT & LON & MMI & TOWN & STATE \\
\hline 42.410 & -113.580 & IV & Albion & ID \\
43.598 & -116.231 & IV $\left(\right.$ III $\left.{ }^{\ddagger}\right)$ & Boise & ID \\
42.012 & -111.804 & IV & Franklin & ID \\
42.950 & -115.307 & IV & Glenns-Ferry & ID \\
43.512 & -114.300 & IV & Hailey & ID \\
42.560 & -113.762 & V & Heyburn & ID \\
43.828 & -115.831 & IV $\left(I^{\ddagger}\right)$ & Idaho-City & ID \\
42.242 & -113.883 & IV & Oakley & ID \\
42.872 & -112.466 & IV & Pocatello & ID \\
42.619 & -113.674 & $\mathrm{~V}$ & Rupert & ID \\
42.937 & -114.405 & $\mathrm{VI}$ & Shoshone & ID \\
42.563 & -114.464 & III & Twin-Falls & ID \\
40.838 & -115.768 & $\mathrm{VI}$ & Elko & NV \\
41.113 & -114.954 & $\mathrm{~V}$ & Wells & NV \\
41.740 & -111.842 & $\mathrm{~V}$ & Logan & UT \\
41.228 & -111.966 & $\mathrm{~V}$ & Ogden & UT \\
40.779 & -111.931 & $\mathrm{~V}$ & Salt-Lake-City & UT \\
41.973 & -112.716 & $\mathrm{~V}$ & Snowville & UT \\
44.775 & -117.832 & FELT & Baker City & OR \\
\hline
\end{tabular}

${ }{ }_{\text {MMI re-evaluated assignment }}$

Table 2. MMI Intensity assignments for the November 11, 1905 earthquake according to Oaks (1992).

As shown in Figure 2, the highest MMI intensity assignments of VI are those at Shoshone, ID, and Elko, NV, which are $259 \mathrm{~km}$ apart. Effects in Shoshone are reported in a special dispatch to the major paper in Boise on the day of the earthquake. The effects described included "knocking dishes from shelves, cracking several stone and brick buildings" and "court house and school house, both being brick buildings, were slightly damaged and the plaster on almost every plastered house in town was more or less injured". This report was the only significant report on effects and damage in Shoshone. The local weekly newspaper in Shoshone gave no information on the earthquake not only in the week following the earthquake but also gave no news on the earthquake in the following months (Oaks, 1992). MMI VI in Elko was assigned from a special dispatch to the major paper in Reno describing the effects as "buildings shook, movable articles rumbled, two chimneys fell, several windows were broken". The local newspaper in Elko reported that "the earthquake was felt all over town". Foreshock activity was also mentioned, while in no other reports of the earthquake foreshock activity was referred to. All of the above suggests the MMI VI assignments at Shoshone and Elko might be biased because archival accounts tend to emphasize the most dramatic effects. Oaks (1992) also noted that these two sites usually experience higher MMI intensities than nearby areas.

Except for Shoshone, most Oaks (1992) intensity assignments in Idaho are III, IV (two of them re-evaluated here) and $\mathrm{V}$. In northern Utah all of the MMI values are $\mathrm{V}$ with minor damage described in the reports. Only two localities in Nevada reported on effects of the earthquake (Table 2). 
The macroseismic field is incomplete with a narrow NW-SE band (Figure 2) in which sites with intensity assignments are concentrated reflecting the characteristics of population density and distribution at the time of the earthquake. All MMI V values are south of $42.56 \mathrm{~N}$ (Heyburn, ID) and north of $40.78 \mathrm{~N}$ (Salt Lake City), enclosing a region at the border between Idaho and Utah although open towards the west and south.

Oaks (1992) obtains $74.941 \mathrm{~km}^{2}$ for the area of isoseismal $\mathrm{V}$ which compares with the areas of $64.225 \mathrm{~km}^{2}, 69.578 \mathrm{~km}^{2}$, and $78.936 \mathrm{~km}^{2}$ for the March 12, 1934 Hansel Valley, UT, earthquake $(E[M]=6.59)$, the August 30,1962 Cache Valley, UT, earthquake $(E[M]=5.72)$, and the March 28, 1975 Pocatello Valley, ID, earthquake $(E[M]=6.01)^{1}$. Using Topozada's (1975) relationship she approximates a local magnitude $M_{\llcorner} 6.0 \pm 1.0$. Oaks (1992) notes that United States seismograms for the 1905 event could not be found but that amplitudes measured on two Milne seismographs operating in Victoria and Toronto, Canada, yielded Ms 4.9 \pm 0.4 .

Based on the MMI intensity field of the November 11, 1905 earthquake as compared with the felt effects of the three earthquakes mentioned above, Oaks (1992) estimated a $M_{\llcorner}$of $5.5 \pm$ 0.5. The epicenter of the earthquake is estimated "at about $42 \mathrm{~N}$ and $113 \mathrm{~W}$ " (Figure 2) based on the interpretation of the two shocks reported at some localities taken as an approximation to the differences between the arrivals of $P$ and $S$ waves (S-P time intervals ranging between $3 \mathrm{~s}$ to $15 \mathrm{~s})$.

\footnotetext{
${ }^{1}$ US Geological Survey combined the MM IV and V isoseismals for the 1975 event.
} 


\section{METHODS}

Three recent analysis techniques to infer the location and magnitude of historical earthquakes are applied to estimate the parameters of the November 11, 1905 earthquake. Those are Bakun and Wentworth (1997), hereafter referred to as B\&W, Gasperini et al. (1999, 2010), hereafter referred to as Boxer, and Musson and Jimenez (2008), hereafter referred to as MEEP. In the determination of earthquake source location and magnitude, these analysis techniques use the geographical location and value of each intensity assignment directly with procedures that are objective, quantitative, and reproducible.

The macroseismic epicenter is an estimation of the location of the center of strong shaking, which does not coincide, in general, with the epicenter as determined from the timing of first arrivals. For earthquakes with magnitude lower than 6.0 and rupture lengths of around $10 \mathrm{~km}$ or less, the difference between the epicenter and the intensity center is comparable to the uncertainty in epicentral determinations while the difference can be much larger for larger earthquakes (Bakun et al. 2011).

All three methods assume a point source and consider the dependence of intensity as a function of magnitude, $f(M)$, and epicentral distance, $g(R)$. Boxer considers as well the dependency on the epicentral intensity. Intensity is considered to increase with magnitude and decrease with epicentral distance (other factors of dependency of intensity including the geological foundation beneath the site are not considered).

The methods of macroseismic location proposed in B\&W and MEEP try to best fit a predictor of ground motion (some kind of attenuation) against intensity data by varying the location and size parameters providing the radiation center of the seismic energy. Boxer instead computes the center of mass (barycenter) of the spatial distribution of the sites experiencing the largest intensities by calculating the average of the geographical coordinates of such sites using a trimmed mean.

\subsection{B\&W}

Bakun and Wentworth (1997) assume an intensity attenuation model of the form:

$$
I=c_{1}+c_{2} M+c_{3} R+c_{4}(\log R)
$$

where $I$ is MMI intensity, $M$ is moment magnitude, $R$ is the hypocentral distance $=\left(r^{2}+h^{2}\right)^{1 / 2}, r$ is epicentral distance, $h$ is the source depth (assumed to be $10 \mathrm{~km}$ ). $c_{1}$ and $c_{2}$ relate the MMI and $\mathrm{M}$ scales, $c_{3}$ can be associated with intrinsic attenuation and scattering, and $c_{4}$ with geometric spreading.

From (1) the magnitude $M_{\iota}$ and rms $\left(M_{\curlywedge}\right)$ are calculated over a grid of trial epicenters.

$$
M_{1}=\operatorname{mean}\left(M_{i}\right) \text {, }
$$

where $M_{\mathrm{i}}$ is the macroseismic magnitude estimated for site $\mathrm{i}$.

$$
\operatorname{rms}\left[M_{1}\right]=\left[\mathrm{rms}\left(M_{\mathrm{l}}-M_{\mathrm{i}}\right)-\mathrm{rms}_{0}\left(M_{\mathrm{l}}-M_{\mathrm{i}}\right)\right],
$$


where rms $\left(M_{1}-M_{\mathrm{i}}\right)=\left\{\Sigma_{\mathrm{i}}\left[\mathrm{W}_{\mathrm{i}}^{*}\left(M_{\mathrm{l}}-M_{\mathrm{i}}\right)\right]^{2} / \Sigma_{\mathrm{i}} \mathrm{W}_{\mathrm{i}}^{2}\right\}^{1 / 2}, \mathrm{rms}_{0}\left(M_{\mathrm{l}}-M_{\mathrm{i}}\right)$ is the minimum rms over the grid of trial epicenters, and $W_{i}$ is the Bakun and Wentworth's (1997) distance weighting function.

The intensity center, IC, is the trial source location for which rms $\left[M_{1}\right]$ is minimum (Bakun, 1999). For earthquakes with sufficient intensity assignments, contours of rms $\left[M_{1}\right]$ bound the epicentral region and these are associated with different levels of confidence for epicenter location. $M_{1}$ at feasible trial source locations within the appropriate confidence-level contours are the best estimates of $\mathrm{M}$ for those source locations. The confidence limits for the epicenter and magnitude in $\mathrm{B} \& \mathrm{~W}$ are estimated as a function of the number of intensity data points (Bakun and Wentworth, 1999).

The resolution of the source location is largely controlled by the quantity, spatial distribution, and internal consistency of the intensity assignments (e.g. Bakun and Scotti, 2006). Events with many, consistent intensity assignments distributed at near sites surrounding the source region can be precisely and reliably located. Events with only a few reliable intensity assignments usually cannot be precisely and reliably located.

A modified B\&W version (Oct. 30, 2008) developed within the European project NERIES (http://emidius.mi.ingv.it/neries NA4/deliverables.php) was used in the calculations.

\subsection{Boxer}

Gasperini et al. $(1999,2010)$ proposed a different method of analysis. The method is called Boxer because the output prescribes a rectangular (box) source region. The algorithm to estimate the macroseismic location first groups all intensity data points (IDPs) into intensity classes and uses the observations in the highest intensity class. If there are less than three, values, those from the next lower intensity class are added. The epicenter (center of mass or barycenter) corresponds to the arithmetic average of the coordinates of the IDPs included in the interval between the 20th and the 80th percentiles. The macroseismic magnitude is computed through a mixed approach combining the assessment of magnitude as a function of epicentral intensity, and as function of the isoseismal areas. This requires two types of calibration functions, one that estimates the magnitude from epicentral intensity, and those that relate magnitude to the area estimated from the mean radius of each intensity class. In order to define the functions, a calibration dataset to perform a region-specific regression is needed.

The regression method:

$$
M_{i}=a+b * \log ^{2} A_{i}+c * I_{0}^{2}
$$

where $M_{i}$ is the magnitude calculated for the i-th intensity class, lo is a calculated epicentral intensity, and $A_{i}$ are the areas of circles with radii equal to the average epicentral distance of sites with a given intensity. The equation is a modification of Sibol et al. (1987) method.

The coefficients are then used to calculate a magnitude $M_{i}$ for each intensity-class mean radius. The calculation and interpretation of $\mathrm{I}_{\mathrm{o}}$ is not always straightforward (Pasolini et al., 2008). Gasperini et al. (1999) assume $I_{0}$ to be equal to the observed $I_{\max }$ if there are at least two values; otherwise $I_{0}$ is set to the second highest observed intensity. A weight is assigned 
to each isoseismal as a function of both the uncertainty in the instrumental magnitude, $\sigma_{\mathrm{M}}$, and of the number IDPs used to compute $A_{i}$.

Once the calibration functions are defined, historical earthquakes can be analyzed by first computing the distance between the estimated macroseismic epicenter and each IDP. A mean radius for each intensity class can then be determined and magnitude is derived from the area and value of each intensity class. The magnitude of the earthquake is computed as the weighted trimmed mean (discarding the highest and lowest estimates) of the magnitudes obtained from each isoseismal.

The earthquake source is represented on the surface by a box centered on the barycenter and oriented along an azimuth fit to the locations of the highest intensity-class sites. The length and width of the box rectangle are derived from Wells and Coppersmith's (1994) empirical relationships.

Boxer computes parameter uncertainties using two different approaches. A formal one estimating the standard deviation of the parameter averages and an empirical one based on bootstrap resampling (Gasperini et al., 2010).

An update of Boxer version 4.0 (Gasperini et al., 2010) was used in the application of the method.

\subsection{MEEP}

The Macroseismic Determination of Earthquake Parameters Technique (MEEP) was developed for use by the European project NERIES (Musson and Jimenez, 2008; Musson, 2009).

In a manner closely based on Boxer location procedure, MEEP uses the highest intensity-class observations to determine an initial centroid epicenter which is equivalent to the Boxer barycenter.

The centroid position is the seed to the remaining procedures and is taken as the starting point in all grid searches in MEEP. It is used as the center of a nine-point $128 \mathrm{~km} \times 128 \mathrm{~km}$ grid search region, with a grid point spacing of $64 \mathrm{~km}$. The search area and the grid spacing are halved iteratively until the grid spacing is $0.5 \mathrm{~km}$ (8 iterations). For each iteration, the grid point with a minimum rms (I) is identified and used as the center of the subsequent grid search iteration.

The epicenter in MEEP is determined by fitting (Kövesligethy, 1906):

$$
I=I_{0}-\{\mathrm{k} \log (r / h)+\mathrm{k} \alpha \log e(r-h)\},
$$

where $I_{o}$ is intensity at epicenter, $r$ is epicentral distance, $h$ is depth, $e$ is Euler's constant, $\mathrm{k}$ is a constant representing isoseismal spacing, and $\alpha$ is anelastic attenuation coefficient. Depth $h$ is assumed for initial iterations and calculated only in the final iteration. As with the Boxer method, the estimation of $I_{0}$ for each iteration might provide some problems (see e.g., Cecić and Musson, 2004). 
Once the estimated epicenter is determined, MEEP uses all the available intensity data and equation (5) to estimate the radii of all the intensity-class isoseismals. The radius of the intensity III isoseismal is taken as the limit of the felt area $A . M_{\mathrm{l}}$ is then calculated from the felt area using Frankel's (1994) attenuation model,

$$
M=\mathrm{n} \log (A / \pi)+\left[2 \mathrm{~m} /\left(2.3 \pi^{0.5}\right)\right] \mathrm{A}^{0.5}+\mathrm{C},
$$

where $\mathrm{n}$ is the geometrical spreading factor (taken to be 0.5), $m=(\pi f) /(Q \beta)$, in which $f$ is the predominant frequency at the limit of the felt area and taken as $3 \mathrm{~Hz}, \mathrm{Q}$ is the shear-wave attenuation quality factor, $\beta$ is the shear-wave velocity, and $C$ is a regional constant.

Even for early historical periods for which very likely reports are restricted to higher damaging intensities, isoseismal expected spacing ( $84 \%$ percentile distance from the epicenter to point of intensity I) is related to the overall felt area through Kövesligethy (1906) model. Thus, given the radius of the expected felt area derived for a range of hypothetical magnitudes, the expected radius of any higher isoseismal can be computed (given the depth). The magnitude, which gives the best match to the observed radii (least squares of residuals), can be considered to be the optimal magnitude determination.

Parameter uncertainties are estimated in MEEP by the 63 percentile values for the absolute differences between the actual computed parameter and 1000 bootstrap resample solutions (Musson 2009).

MEEP 2.01 version was used in the application of the method (Musson, 2009). 


\section{CALIBRATION}

\subsection{Set of calibration events}

The three techniques for determining location and magnitude of historical earthquakes require appropriate intensity attenuation regional models. These attenuation models are obtained through processing a set of regional calibration events covering the paths across the region of study.

From the 16 earthquakes extracted from the INL_SL3 catalog (see section 2.1 and Table 1), a subset of seven earthquakes have been selected for calibration purposes. Table 3 lists the location parameters, magnitude, and macroseismic information. The locations of the calibration events are shown in Figure 3a. Figure $3 b$ depicts the full set of intensity observations $(1,900$ IDPs with $\mathrm{MMI} \geq \mathrm{III})$ in the macroseimic fields of the calibration set.

Each calibration event has a minimum of $60 \mathrm{MMI} \geq \mathrm{IV}$ values extracted from NOAA database, a maximum intensity larger or equal than $\mathrm{V}$, and at least three levels of MMI intensities represented in the macroseismic field, mostly distributed in the area of selection. Although data from NOAA include IDP values down to $M M I=2$, and also sites without MMI intensity assignments, the selected working sets of IDPs for each calibration earthquake considered only sites with $\mathrm{MMI} \geq \mathrm{III}$. The threshold of at least $60 \mathrm{MMI} \geq \mathrm{IV}$ is set to include as much information as possible from higher levels of MMI intensity likely less uncertain as compared to those of lower degrees.

Individual earthquake maximum $\mathrm{MMI}$ intensity in the calibration set range from $X$ (August 18, 1959 ) to $V$ (August 22, 1984). The number of MMI $\geq$ IV range from 624 (August 18, 1959) to 62 (August 22, 1984).

\begin{tabular}{cccccccc}
\hline DATE & LAT & LON & E[M] & Location & Imax & MMI $\geq$ IV & MMI $\geq$ III \\
\hline $1934-03-12$ & 41.658 & -112.795 & 6.59 & Hansel Valley, UT & VIII & 105 & 152 \\
$1944-07-12$ & 44.412 & -115.063 & 6.18 & southern Idaho & VII & 75 & 86 \\
$1959-08-18$ & 44.830 & -111.000 & 7.23 & Hebgen Lake, MT & $X$ & 624 & 635 \\
$1962-08-30$ & 42.035 & -111.741 & 5.72 & Cache Valley, UT & VII & 222 & 251 \\
$1975-03-28$ & 42.063 & -112.525 & 6.01 & Pocatello, ID & VIII & 143 & 188 \\
$1983-10-28$ & 43.967 & -113.899 & 6.89 & Borah Peak, ID & VII & 384 & 462 \\
$1984-08-22$ & 44.377 & -114.081 & 5.55 & Devil Canyon, ID & V & 62 & 126
\end{tabular}

Table 3. Set of calibration earthquakes in the area extending from $117 \mathrm{~W}$ to $110 \mathrm{~W}$, and $40 \mathrm{~N}$ to 45N, for the time period 1850-2020. E[M]: uniform moment magnitude estimate, Imax: Maximum intensity, $\mathbf{M M I} \geq I \mathrm{~V}$ : number of intensity data with $M M I \geq I V, M M I \geq I I I:$ number of intensity data with $M M I \geq I I$. 


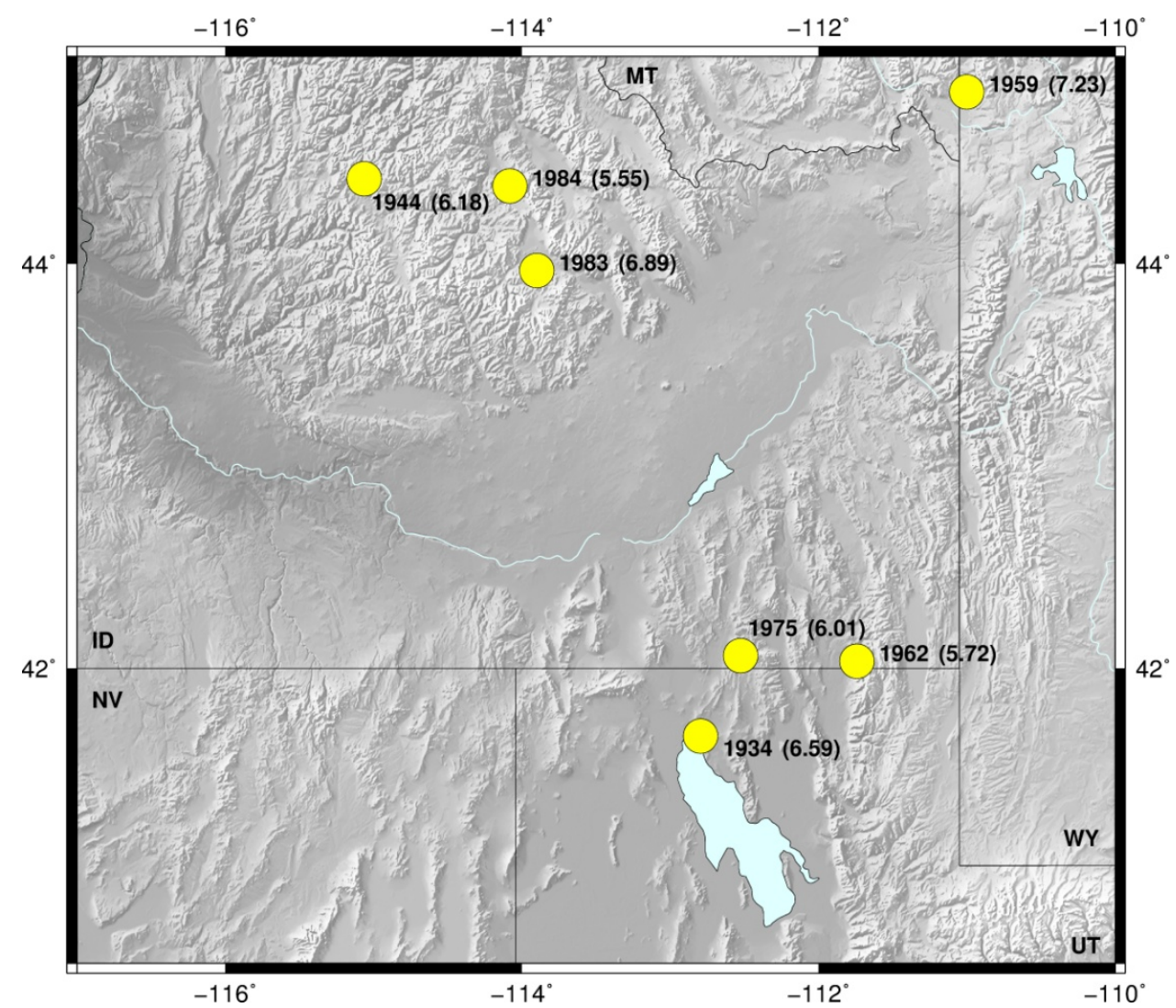

Figure 3a. Set of calibration earthquakes.

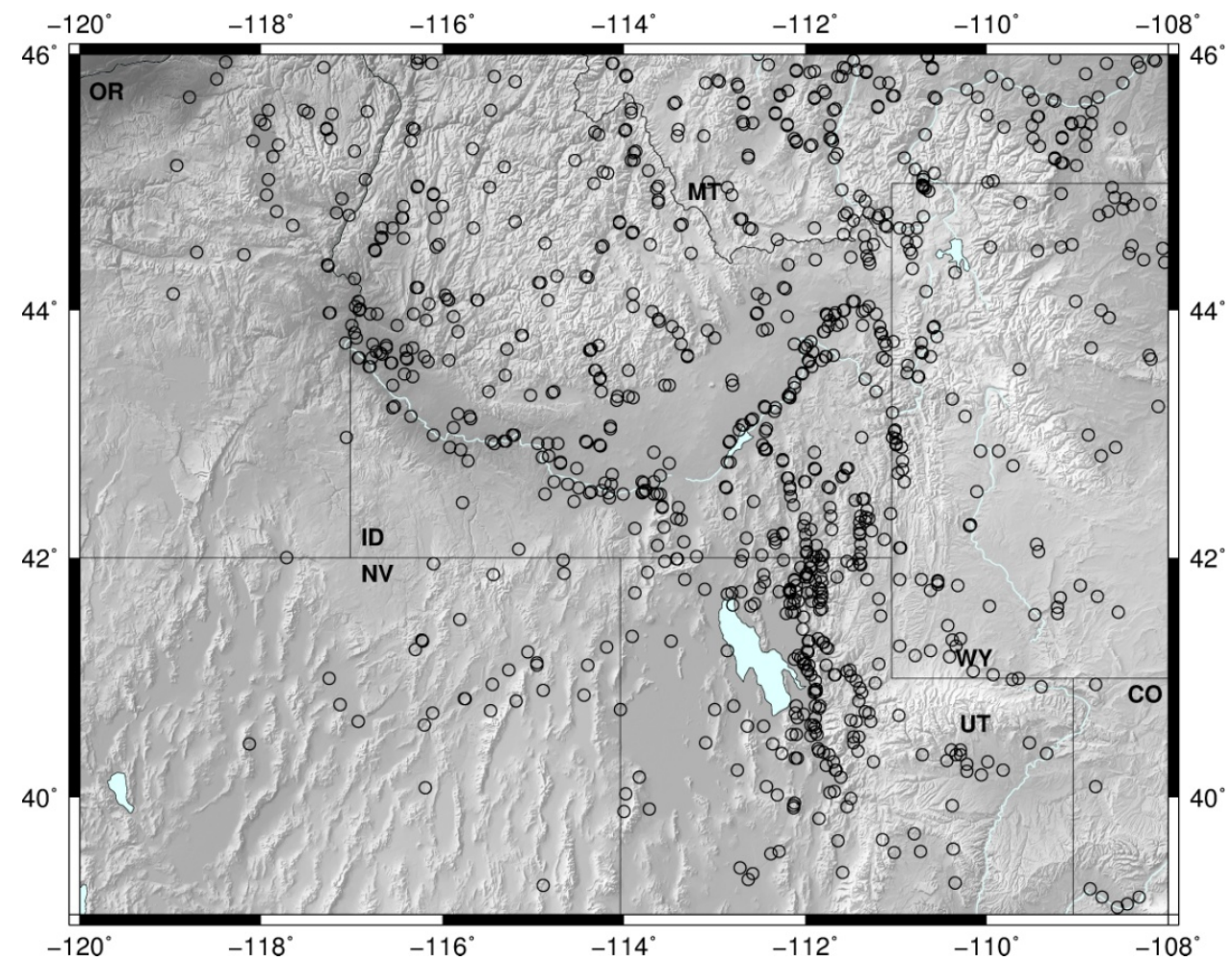

Figure 3b. 1,900 IDPs (MMI $\geq I I I)$ in the macroseimic fields of the set of calibration earthquakes 
Calibration procedures were run for Boxer and MEEP approaches. For B\&W technique the attenuation model for the Basin and Range (B\&R) region as specified in Bakun (2006) was adopted (see section 4.2). The next sections detail the procedures and the results of the calibration.

\subsection{B\&W}

There are three regional $\mathrm{MMI}$ attenuation models in the literature for estimating $\mathrm{M}$ for earthquakes in the interior western North America using the technique of B\&W (Bakun et al., 2002 and Bakun, 2006). Among these models, that in Bakun (2006) specifically developed for the Basin and Range province was adopted.

For earthquakes in the Basin and Range province, Bakun (2006) developed a modified Mercalli intensity (MMI) attenuation model of the form:

$$
\mathrm{MMI}=(0.44 \pm 2.34)+(1.70 \pm 0.33) \mathrm{M}-(0.0048 \pm 0.0014) \mathrm{R}-(2.73 \pm 0.49) \log \mathrm{R}
$$

where the hypocentral distance $\mathrm{R}$ is in kilometers and depth $\mathrm{h}$ is fixed to $10 \mathrm{~km}$.

The choice of Bakun (2006) Basin and Range attenuation, which is appropriate for earthquakes in the Utah-Idaho border region, is based on a first MEEP centroid estimation of the macroseismic epicenter of the November 11, 1905 earthquake. The centroid estimation is entirely based on the macroseismic intensity field giving a first estimate of the epicentral region with no assumptions on attenuation (see Fig. 5 for MEEP centroid location).

\subsection{Boxer}

Boxer code (Gasperini et al, 1999, 2010) includes an optional procedure to compute the coefficients of the magnitude-intensity empirical relationships based on a method modified from Sibol et al. (1987).

Values of the magnitude standard deviation, $\sigma_{\mathrm{M}}$, and the epicentral intensity, $\mathrm{I}_{\mathrm{o}}$, are required for applying that procedure. Following Gasperini et al. (2010), a value of $\sigma_{M}=0.5$ is used, and $\mathrm{I}_{\mathrm{o}}$ is defined as the maximum intensity with at least two IDPs.

The calibration procedure has included the selected set of seven earthquakes as described above for the determination of the coefficients in equation (4). Results are summarized in Table 4. Note that Boxer fixes coefficient $\mathrm{c}$ to 0 and recomputes the regression with respect only to $a$ and $b$ when the test of significance for the dependence of $c$ on $I_{0}$ fails. This usually happens for high intensity classes for which magnitude is almost independent of $\mathrm{I}_{\mathrm{o}}$ (see levels IV to VI in Table 4).

Results of the estimation of the macroseismic location and magnitude of the individual events in the calibration set by applying the Boxer calibrated parameters are given in Table 5 and figures in Appendix A. 
Table 5 lists the Boxer macroseismic locations as compared with the epicentral locations in the INL_SL3 catalog including the distance in $\mathrm{km}$ between both epicenters and the differences in estimated Boxer macroseismic magnitude with respect to $E[M]$ in the catalog.

The location differences range from $6 \mathrm{~km}$ to $35 \mathrm{~km}$. In all cases except two, these differences are less than $20 \mathrm{~km}$. The differences in the Boxer macroseismic magnitudes with respect to the INL_SL3 catalog range from -0.35 to 0.01 . All of the differences are less than 0.20 if Boxer magnitude is below E[M]. Only in two cases Boxer magnitudes are 0.23 or 0.35 above the catalog magnitude.

\begin{tabular}{ccccccc} 
MMI class & $\mathbf{a}$ & $\mathbf{b}$ & $\mathbf{c}$ & $\mathbf{s t d}$ & $\mathbf{w}$ & DOF \\
\hline III & 1.82810 & 0.12234 & 0.02043 & 0.1646 & 42.7143 & 4 \\
IV & 2.35560 & 0.14992 & 0.00000 & 0.2894 & 74.7143 & 5 \\
V & 3.06152 & 0.13733 & 0.00000 & 0.2131 & 115.1667 & 4 \\
VI & 3.80543 & 0.13616 & 0.00000 & 0.0685 & 51.3333 & 4 \\
\hline
\end{tabular}

Table 4. Boxer calibration parameters.

\begin{tabular}{|c|c|c|c|c|c|c|c|c|}
\hline \multirow[b]{2}{*}{ DATE } & \multicolumn{3}{|c|}{ INL_SL3 catalog } & \multicolumn{3}{|c|}{ Boxer } & \multirow[b]{2}{*}{ dist (km) } & \multirow[b]{2}{*}{ diffM } \\
\hline & LAT & LON & $E[M]$ & LAT & LON & M & & \\
\hline 1934-03-12 & 41.658 & -112.795 & 6.59 & 41.693 & -112.743 & 6.41 & 6 & 0.18 \\
\hline 1944-07-12 & 44.412 & -115.063 & 6.18 & 44.320 & -115.013 & 6.01 & 11 & 0.17 \\
\hline $1959-08-18$ & 44.830 & -111.000 & 7.23 & 44.860 & -111.347 & 7.22 & 28 & 0.01 \\
\hline $1962-08-30$ & 42.035 & -111.741 & 5.72 & 41.938 & -111.833 & 5.95 & 13 & -0.23 \\
\hline 1975-03-28 & 42.063 & -112.525 & 6.01 & 42.077 & -112.323 & 5.91 & 17 & 0.10 \\
\hline $1983-10-28$ & 43.967 & -113.899 & 6.89 & 44.105 & -113.935 & 6.95 & 16 & 0.06 \\
\hline $1984-08-22$ & 44.377 & -114.081 & 5.55 & 44.676 & -114.220 & 5.90 & 35 & -0.35 \\
\hline
\end{tabular}

Table 5. Macroseismic Boxer epicenter and magnitude differences with respect to catalog parameters for the seven events in the calibration set. dist $(\mathbf{k m})$ : distance in $\mathrm{km}$ between epicenters, diffM: difference in magnitude values.

Figures A.1 to A.7 in Appendix A show the results of Boxer macroseismic epicenter locations as compared to the epicentral locations in the INL_SL3 catalog. 


\subsection{MEEP}

MEEP code (Musson and Jiménez, 2008; Musson, 2009) also includes an optional procedure (CALIMEEP) to compute the isoseismal spacing, $\mathrm{k}$, of the Kövesligethy (1906) model, and the regional constant, $C$, of Frankel's (1994) model. CALIMEEP requires values of the regional anelastic attenuation coefficient, $\alpha$, the $3 \mathrm{~Hz}-\mathrm{Q}$ value, and the shear-wave velocity, $\beta$.

From recent literature (Aleqabi and Wysession, 2006; Eulenfeld and Wegler, 2017; Moschetti et al, 2010; Gallegos et al, 2017), selected values are $\alpha=0.0045$ and $Q_{3 \mathrm{~Hz}}=600$ from Gallegos et al (2017), and $\beta=3.5 \mathrm{~km} / \mathrm{s}$ from Moschetti et al (2010). As in the Boxer technique, the MEEP calibration procedure was run on the selected set of seven earthquakes.

\begin{tabular}{cc}
\hline Parameter & Value \\
\hline$Q_{3 \mathrm{~Hz}}$ & $600^{1}$ \\
$\alpha$ & $0.0045^{1}$ \\
$\beta$ & $3.5 \mathrm{~km} / \mathrm{s}^{1}$ \\
$\mathrm{C}$ & $2.26^{2}$ \\
$\mathrm{k}$ & $3.60^{2}$ \\
\hline${ }^{1}$ regional values from literature & \\
${ }^{2}$ computed values &
\end{tabular}

Table 6. MEEP calibration parameters

Table 6 lists the complete list of parameters. The scaling constant $C$ value of 2.26 is within the values found by Frankel (1994) of 1.74 and 2.53 for stable continental crust and California respectively. The value of 3.60 computed for the isoseismal spacing $k$ is within the range of typical values lying between 2.0 and 4.0 (Musson, 2009).

Results of the estimation of macroseismic location and magnitude of the individual events in the calibration set by applying the MEEP procedure with the calibrated parameters are given in Table 7 and figures in Appendix A.

Table 7 lists the MEEP macroseismic locations as compared with the epicentral locations in the INL_SL3 catalog including the distance in $\mathrm{km}$ between both epicenters and the differences in estimated MEEP macroseismic magnitude with respect to $E[M]$ in the catalog.

Macroseismic locations range from 8 to $30 \mathrm{~km}$ distance from the INL_SL3 catalog epicenter locations. The differences in the MEEP macroseismic magnitudes with respect to the E[M] catalog magnitudes are in the range -0.35 to 0.38 . For MEEP magnitude lower than the catalog magnitude the differences are between 0.11 and 0.38 , otherwise the differences lie between 0.21 and -0.35 . 


\begin{tabular}{|c|c|c|c|c|c|c|c|c|}
\hline \multirow[b]{2}{*}{ DATE } & \multicolumn{3}{|c|}{ INL_SL3 catalog } & \multicolumn{3}{|c|}{ MEEP } & \multirow[b]{2}{*}{ dist (km) } & \multirow[b]{2}{*}{ diffM } \\
\hline & LAT & LON & $\mathrm{E}[\mathrm{M}]$ & LAT & LON & M & & \\
\hline 1934-03-12 & 41.658 & -112.795 & 6.59 & 41.677 & -112.708 & 6.30 & 8 & 0.29 \\
\hline $1944-07-12$ & 44.412 & -115.063 & 6.18 & 44.588 & -115.353 & 5.80 & 30 & 0.38 \\
\hline $1959-08-18$ & 44.830 & -111.000 & 7.23 & 44.904 & -111.287 & 7.10 & 24 & 0.13 \\
\hline $1962-08-30$ & 42.035 & -111.741 & 5.72 & 41.899 & -111.835 & 6.00 & 17 & -0.28 \\
\hline $1975-03-28$ & 42.063 & -112.525 & 6.01 & 42.031 & -112.411 & 5.90 & 10 & 0.11 \\
\hline $1983-10-28$ & 43.967 & -113.899 & 6.89 & 44.052 & -113.842 & 7.10 & 10 & -0.21 \\
\hline 1984-08-22 & 44.377 & -114.081 & 5.55 & 44.601 & -114.137 & 5.90 & 25 & -0.35 \\
\hline
\end{tabular}

Table 7. Macroseismic MEEP epicenter and magnitude differences with respect to catalog parameters for the seven calibration events. dist $(\mathbf{k m})$ : distance in $\mathrm{km}$ between epicenters, diffM: difference in magnitude values.

Figures A.1 to A.7 in Appendix A show the results of MEEP macroseismic epicenter locations as compared to the epicentral locations in the INL_SL3 catalog.

\subsection{Validation events}

The calibration parameters as determined for Boxer and MEEP, and the adopted attenuation model for B\&W are validated by running the procedures with the most recent instrumental earthquakes fulfilling the same selection criteria as for the set of calibration events.

During the first stages of this work only one recent $M \geq 5.5$ earthquake with intensity data was found for the area of interest, the February 21, 2008 (Wells, NV). Two $M \geq 5.5$ earthquakes have occurred very recently in the area, the March 18, 2020 (Magna, UT) and the March 31, 2020 (Stanley, ID) providing new data with instrumentally determined parameters. The set of validation events includes these three events which are listed in Table 8.

\begin{tabular}{|c|c|c|c|c|c|c|c|}
\hline DATE & LAT & LON & $E[M]$ & Location & Imax & $\mathbf{M M I} \geq \mathrm{IV}^{1}$ & $M M I \geq I^{1}$ \\
\hline $2008-02-21$ & 41.144 & -114.872 & 5.97 & Wells, NV & VII & 43 & 150 \\
\hline 2020-03-18 & 40.751 & -112.078 & 5.57 & NNW Magna, UT & VII & 126 & 275 \\
\hline 2020-03-31 & 44.460 & -115.136 & 6.45 & NW Stanley, ID & VIII & 494 & 1131 \\
\hline
\end{tabular}

${ }^{1} \mathrm{DYFI}$ CDI geocoded $10 \mathrm{~km}$

Table 8. Set of validation events. E[M]: uniform moment magnitude estimate, Imax: Maximum intensity, $M M I \geq I V$ : number of intensity data with $M M I \geq I V, M M I \geq I I$ : number of intensity data with $M M I \geq I I I$. 


\begin{tabular}{|c|c|c|c|c|c|c|c|c|}
\hline \multirow[b]{2}{*}{ DATE } & \multicolumn{3}{|c|}{ INL_SL3 catalog } & \multicolumn{3}{|c|}{ B\&W } & \multirow[b]{2}{*}{ dist (km) } & \multirow[b]{2}{*}{ diffM } \\
\hline & LAT & LON & $E[M]$ & LAT & LON & $\mathbf{M}$ & & \\
\hline $2008-02-21$ & 41.144 & -114.872 & 5.97 & 41.275 & -114.735 & 6.04 & 19 & -0.07 \\
\hline $2020-03-18$ & 40.751 & -112.078 & 5.57 & 40.885 & -112.305 & 5.59 & 24 & -0.02 \\
\hline 2020-03-31 & 44.460 & -115.136 & 6.45 & 44.730 & -115.005 & 6.45 & 32 & 0.00 \\
\hline
\end{tabular}

Table 9. Macroseismic B\&W epicenter and magnitude differences with respect to catalog parameters for the three events in the validation set. dist ( $\mathbf{k m})$ : distance in $\mathrm{km}$ between epicenters, diffM: difference in magnitude values.

\begin{tabular}{|c|c|c|c|c|c|c|c|c|}
\hline \multirow[b]{2}{*}{ DATE } & \multicolumn{3}{|c|}{ INL_SL3 catalog } & \multicolumn{3}{|c|}{ Boxer } & \multirow[b]{2}{*}{ dist (km) } & \multirow[b]{2}{*}{ diffM } \\
\hline & LAT & LON & $\mathrm{E}[\mathrm{M}]$ & LAT & LON & M & & \\
\hline $2008-02-21$ & 41.144 & -114.872 & 5.97 & 41.073 & -115.157 & 6.10 & 25 & -0.13 \\
\hline 2020-03-18 & 40.751 & -112.078 & 5.57 & 40.668 & -112.038 & 5.47 & 10 & 0.10 \\
\hline 2020-03-31 & 44.460 & -115.136 & 6.45 & 44.455 & -114.740 & 6.54 & 31 & -0.09 \\
\hline
\end{tabular}

Table 10. Macroseismic Boxer epicenter and magnitude differences with respect to catalog parameters for the three events in the validation set. dist ( $\mathbf{k m})$ : distance in $\mathrm{km}$ between epicenters, diffM: difference in magnitude values.

\begin{tabular}{|c|c|c|c|c|c|c|c|c|}
\hline \multirow[b]{2}{*}{ DATE } & \multicolumn{3}{|c|}{ INL_SL3 catalog } & \multicolumn{3}{|c|}{ MEEP } & \multirow[b]{2}{*}{ dist (km) } & \multirow[b]{2}{*}{ diffM } \\
\hline & LAT & LON & $E[M]$ & LAT & LON & $\mathbf{M}$ & & \\
\hline $2008-02-21$ & 41.144 & -114.872 & 5.97 & 41.159 & -114.995 & 6.1 & 10 & -0.13 \\
\hline $2020-03-18$ & 40.751 & -112.078 & 5.57 & 40.770 & -112.084 & 5.9 & 2 & -0.33 \\
\hline $2020-03-31$ & 44.460 & -115.136 & 6.45 & 44.484 & -114.804 & 6.5 & 26 & -0.05 \\
\hline
\end{tabular}

Table 11. Macroseismic MEEP epicenter and magnitude differences with respect to catalog parameters for the three validation events. dist $(\mathbf{k m})$ : distance in $\mathrm{km}$ between epicenters, diffM: difference in magnitude values.

Equivalent $\mathrm{MMI}$ for the set of validation events is obtained from Community Decimal Intensities (CDI) values in DYFI data (no direct MMI assignments are provided in NOAA databases for earthquakes after 1985). MMI in DYFI databases is provided for aggregated DYFI city/ZIP maps (under DYFI responses in the event DYFI page) by rounding decimal CDIs to obtain an equivalent MMI. 
Boundaries in City/ZIP maps are often irregularly shaped or too large in low-population density areas while aggregated geocoded values with $10 \mathrm{~km}$ spacing give greater precision in location intensities (https://earthquake.usgs.gov/data/dyfi/background.php). Dengler and Dewey (1998) show that CDI values are consistent with traditionally assigned intensities but are characterized by much less scatter.

Equivalent $\mathrm{MMI}$ as converted from $10 \mathrm{~km}$ spacing aggregated geocoded $\mathrm{CDI}$ values are used in the validation procedure.

The results of the validation test for the three methods are given in Table $9(B \& W)$, Table 10 (Boxer) and Table 11 (MEEP), and figures B1 to B3 in Appendix B, respectively.

For the February 21, 2008 (Wells, NV) event, the estimated macroseismic magnitudes reach at the most 0.13 difference above the INL_SL3 magnitude. The macroseismic locations (Figure B.1) range from $10 \mathrm{~km}$ (MEEP) to $25 \mathrm{~km}$ (Boxer) distance from the catalog location.

The estimated macroseismic magnitudes for the March 18, 2020 (Magna, UT) event range from 0.33 above the INL_SL3 value to 0.10 lower than the catalog value. The distances between the macroseismic epicenter and the INL_SL3 epicenter (Figure B.2) are $24 \mathrm{~km}$ (B\&W), $10 \mathrm{~km}$ (Boxer), and $2 \mathrm{~km}$ (MEEP) apart.

The magnitude differences for the March 31, 2020 (Stanley, ID) range from -0.09 to 0.00 . The macroseismic locations are around $30 \mathrm{~km}$ apart from the INL_SL3 location (Figure B.3). As compared to the other two events in the validation set, the distances between the catalog and the computed epicenter locations are greater in this case.

The macroseismic estimates of magnitude and location based on the MMI assignments for the three events in the validation set suggest that the calibration procedures and parameters obtained for each of the three approaches are appropriate for earthquakes occurring in the investigated region. 


\section{THE NOVEMBER 11, 1905 EARTHQUAKE PARAMETERS}

The intensity assignments of the November 11, 1905 earthquake are analyzed using the three approaches described in former sections to estimate the macroseismic epicentral location and magnitude and associated uncertainties.

\subsection{Analysis of incomplete Intensity data}

It is quite often that the collection of intensity assignments for historical earthquakes is not complete which results in a spatially biased set of intensity assignments. Such is the case of the November 11, 1905 event where most of the sites with intensity assignments are concentrated in a NW-SE narrow band and higher levels of intensity are very poorly represented in the macroseismic field. In these cases, macroseismic methods based on grid search procedures (B\&W and MEEP) might provide the best estimates of macroseismic magnitude by using subsets of intensity assignments that are not spatially biased. In their application of the B\&W approach, Bakun and Scotti (2006) results suggest that for events with apparently incomplete distribution of IDPs, the macroseismic magnitude $M_{1}$ should be estimated using intensity assignments for only those intensity levels with apparently complete distribution.

To explore if the use of only those intensity levels with apparently complete distributions provide unbiased estimates of MEEP and B\&W macroseismic magnitudes, subsets of intensity assignments of two of the earthquakes in the calibration set located in the Idaho-Utah border region (the August 30, 1962 and the March 28, 1975) are tested here. Using only the levels V and IV of the intensity assignments of the August 30, 1962 Cache Valley, UT, earthquake with $E[M]=5.72$ (Figure A.4) and the March 28, 1975 Pocatello, ID, earthquake with $E[M]=6.01$ (Figure A.5) the MEEP estimated macroseismic magnitudes are 6.1 and 6.1, while the B\&W estimates are 6.2 and 6.2, respectively. If using all of the intensity assignments, MEEP estimated magnitudes are 6.0 and 5.9 while B\&W estimated magnitudes are 6.2 and 6.0, respectively. These differences are within the expected uncertainty.

These results indicate that in the case of events with incomplete distributions of intensity assignments, B\&W and MEEP unbiased estimates of macroseismic magnitude can be obtained by using intensity assignments for only those intensity levels with apparently complete distributions. Accordingly, in the macroseismic epicenter and magnitude determinations of the 11 November, 1905 the most complete intensity levels are intensities $\mathrm{V}$ and IV and will be used in the analyses.

\section{$5.2 \mathrm{~B} \& W$}

As noted in section 3.1, the resolution of the intensity center, IC, of the B\&W technique is controlled by the quantity, the spatial distribution, and the internal consistency of the IDPs. Events with only a few reliable intensity assignments such as the November 11, 1905 usually cannot be precisely and reliably located.

The B\&W estimates for location and $\mathrm{M}$ for the 1905 earthquake are based on the apparently most complete intensity levels of MMI V and IV (see section 5.1). The intensity center, IC, is located at 40.964N and 113.405W (Figure 4). 


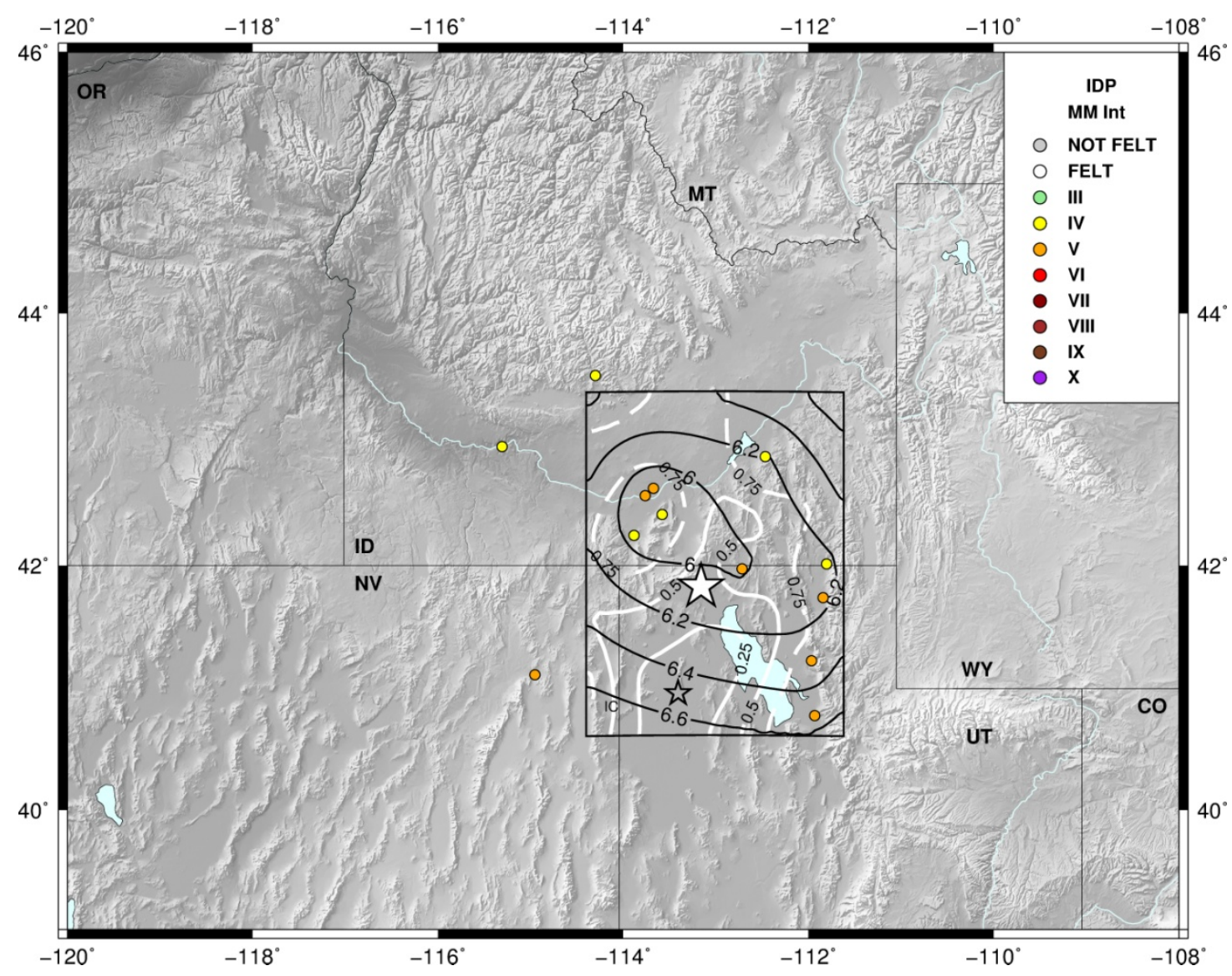

Figure 4. The November 11, 1905 event using the Basin and Range regional attenuation model in Bakun (2006). Colored circles are sites with intensity assignments IV and V. The IC is shown as an open black star. Solid white star: local rms $\left[M_{i}\right]$ minimum. Contours of $M_{l}$ are solid black lines. White lines: $r m s\left[M_{1}\right]$ contours. Solid white lines highlight rms $\left[M_{1}\right]$ contours of 0.25 (inner contour) and 0.50 (outer contour).

The IC can be discounted as a credible source because it is far away from any region with MMI intensity observations. This is an effect of B\&W best-fit method, which in this case locates the intensity center to the SW of the searched region and away from apparently inconsistent intensity assignments. The MMI V and MMI IV fields used are the most complete although much less covered by observations to the SW azimuth. $r m s\left[M_{1}\right]$ contours are elongated towards the SW in the direction of the greater azimuthal gap in intensity assignments.

The results of the grid search in Figure 4 show a local minimum region, which is enclosed by the outer $0.50 \mathrm{rms}\left[\mathrm{M}_{1}\right]$ contour. The 0.50 and $0.25 \mathrm{rms}\left[\mathrm{M}_{1}\right]$ in Figure 4 (outer and inner solid white line contours) roughly correspond to the $95 \%(0.488)$ and $67 \%(0.205)$ confidence levels values for location from Bakun and Wentworth (1999).

The preferred location at the rms $\left[\mathrm{M}_{\mathrm{l}}\right]$ local minimum is $41.830 \mathrm{~N}$ and $113.160 \mathrm{~W}$. The $\mathrm{B} \& \mathrm{~W}$ macroseismic magnitude $M_{1}$ for a source at the preferred location is 6.05 . 


\subsection{Boxer}

The application of Boxer method using all intensity assignments of the November 11, 1905 earthquake results in a location of the macroseismic epicenter at $41.722 \mathrm{~N}$ and $113.306 \mathrm{~W}$ and a macroseismic magnitude of 6.02. If only levels $\mathrm{V}$ and IV of the intensity assignments are used, the macroseismic epicenter location obtained is $41.722 \mathrm{~N}$ and $112.810 \mathrm{~W}$ and the macroseismic magnitude is 5.87 . The latitude is the same in both determinations while the longitude is slightly towards the west when determined with all intensity assignments. In this last case the two MMI VI values are added to the MMI V assignments in the barycenter determination, causing a drift to the west of the center of mass. The macroseismic magnitude estimations difference is 0.15 magnitude units. Although Boxer is able to provide unbiased magnitude estimations either by using the complete macroseismic field or by using only a subset of intensity levels, the inclusion of the likely uncertain MMI VI assignments (see section 2.2 ) is most probably introducing some bias in the location results. Figure 5 shows Boxer location of macroseismic epicenter when using MMI V and IV subset.

Boxer estimates as well the earthquake source which is represented on the surface by a box. The box is centered on the barycenter and oriented along an azimuth fit to the locations of the highest intensity-class sites with the length and width of the box taken from Wells and Coppersmith's (1994) empirical relationships. Table 12 gives the Boxer estimated parameters of the earthquake source.

\begin{tabular}{ccc}
\hline \multicolumn{3}{c}{ FAULT PARAMETERS } \\
\hline Azimuth & Length $(\mathbf{k m})$ & Width $(\mathbf{k m})$ \\
$128.7 \pm 24.7$ & $10.5 \pm 3.2$ & $7.4 \pm 1.3$ \\
\hline
\end{tabular}

Table 12. Boxer fault parameters for the November 11, 1905 earthquake

\subsection{MEEP}

The first step in the procedure of MEEP code is the estimation of the centroid of the higher IDPs in a manner closely based on Gasperini et al. (1999). The centroid is based on a data set trimmed of outliers with approximately $25 \%$ of points being eliminated with no assumption of an intensity attenuation model. The MEEP macroseismic centroid, using intensity levels $\mathrm{V}$ and IV, is estimated at $42.030 \mathrm{~N}$ and $112.779 \mathrm{~W}$ and an estimated macroseismic magnitude of 6.1 .

Based on the calibrated parameters as detailed in section 4 and further validation with very recent events (section 4.4), and using intensity levels $V$ and IV (see section 5.1), the estimated macroseismic epicenter resulting from the MEEP grid search procedure is at $42.188 \mathrm{~N}$ and $112.885 \mathrm{~W}$ with an estimated macroseismic magnitude of 6.0 . Figure 5 shows the location of both the macroseismic centroid and the macroseismic epicenter. 


\subsection{Macroseismic location and magnitude of the November 11, 1905 earthquake}

The results on the macroseismic estimation of epicenter location and magnitude of the November 11, 1905 event are summarized in Table 13. Figure 5 shows the locations as estimated by the different methods including as well the Oaks (1992) and the centroid locations. There is consistency among the different methods in the estimation of the location and magnitude of the November 11, 1905 earthquake. All macroseismic epicenter locations concentrate in a region at the Utah-Idaho border region. The centroid and MEEP locations are very close to the Oaks (1992) determination. Boxer and the preferred B\&W epicenter (B\&W grid search local minimum) are slightly to the south and southwest of the Oaks (1992) epicenter, respectively. Estimated macroseismic magnitudes by each of the three methods are in good agreement around 6.0, and all are above the 5.5 value and within its variability of \pm 0.5 estimated by Oaks (1992).

\begin{tabular}{cccccc}
\hline method & LAT & LON & ERH $(\mathbf{k m})$ & M & ERM \\
\hline B\&W & 41.830 & -113.160 & - & 6.05 & - \\
Boxer & 41.722 & -112.810 & $35.1 ; 37.8 / 33.0 ; 45.5$ & 5.87 & $0.7 / 0.3$ \\
MEEP & 42.188 & -112.885 & 80.2 & 6.00 & 0.3 \\
\hline
\end{tabular}

${ }^{1}$ Preferred location from B\&W analyses (see details in section 5.2)

Table 13 Location (LAT, LON) and magnitude (M) solutions by the three methods (B\&W, Boxer, MEEP) ERH: Location uncertainty. ERM: Magnitude uncertainty. Boxer gives two uncertainty values (formal / bootstrap), for both coordinates (LAT; LON) and magnitude. MEEP single value correspond to the 63 percentile value for the absolute differences between the solution and the bootstarp resampling (see text for details)

The three methods applied use bootstrap resampling as an approach to estimate parameter uncertainties (e.g. Bakun and Scotti, 2006; Gasperini et al 2010; Musson 2009). Boxer also estimates formal uncertainties calculated by the standard deviation of the parameter averages.

Table 13 summarizes the results of the uncertainty estimates directly given by the methods. Boxer bootstrap uncertainty estimates give the standard deviation of the bootstrap solutions while MEEP uncertainties represent the 63 percentile values for the absolute differences between the actual computed parameter and the 1000 bootstrap solutions. No uncertainty is given in Table 13 for the B\&W estimations because the epicenter and magnitude correspond to the preferred location at the local minimum of the searched region and not at the location of the intensity center.

To allow for a direct comparison of the results and associated uncertainties in the parameters, Table 14 gives the uncertainties as represented by the $68 \%$ percentile confidence interval, $\mathrm{Cl}$, of the 1000 bootstrap solutions $\left(16^{\text {th }}\right.$ and $84^{\text {th }}$ percentiles in the distribution). An orange rectangle in Figure 5 (Latitudes $41.550 \mathrm{~N}$ and $42.060 \mathrm{~N}$ and Longitudes 113.478W and 
112.320W) encloses the common region of both Boxer and MEEP 68\% percentile confidence intervals. The centroid solution, the Oaks (1992) location, and the B\&W preferred location are inside this region.

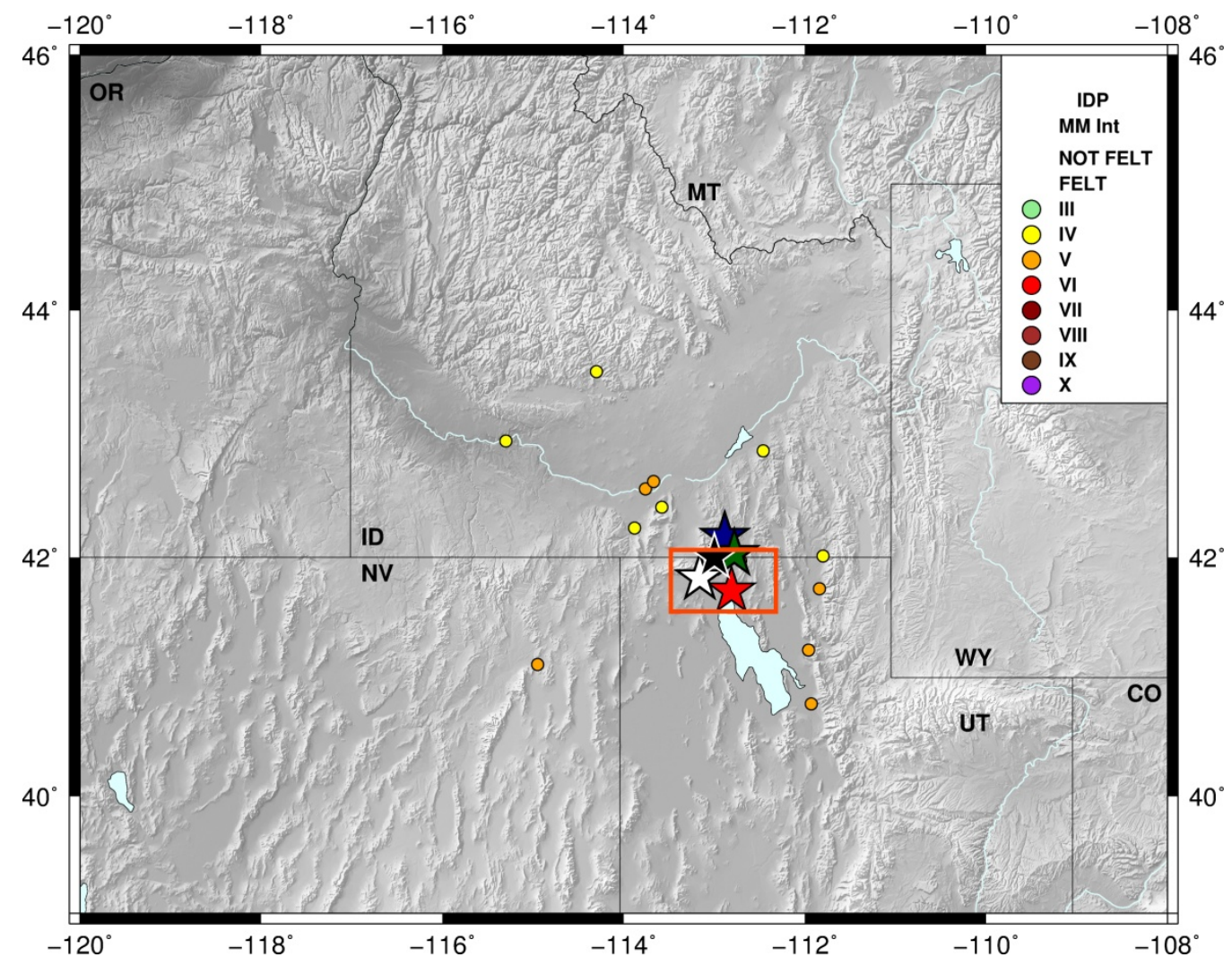

Figure 5. The November 11, 1905 macroseismic epicenter locations. Star colors for epicenter locations are as follows: Centroid - green; Oaks (1992) - black; Boxer - red; B\&W - white; and MEEP - blue. Colored circles are sites with IV and $V$ intensity assignments. Orange rectangle shows the common region of the bootstrap $68 \% \mathrm{Cls}$ from Boxer and MEEP

\begin{tabular}{ccccccc}
\hline method & LAT & Bootstrap 68\% Cl & LON & Bootstrap 68\% Cl & M & Bootstrap 68\% Cl \\
\hline B\&W & 41.830 & - & -113.160 & - & 6.05 & - \\
Boxer & 41.722 & {$[41.358 ; 42.060]$} & -112.810 & {$[-113.478 ;-112.320]$} & 5.87 & {$[5.52 ; 6.03]$} \\
MEEP & 42.188 & {$[41.550 ; 42.520]$} & -112.885 & {$[-113.730 ;-112.288]$} & 6.00 & {$[5.70 ; 6.40]$} \\
\hline
\end{tabular}

Table 14 Final location (LAT, LON) and magnitude (M) solutions by the three methods (B\&W, Boxer, MEEP) with empirical estimation of uncertainties by the $68 \%$ percentile interval of the 1000 bootstrap solutions (Bootstrap 68\% Cl) 


\section{CONCLUDING REMARKS}

The three techniques applied use different approaches for estimating macroseismic earthquake parameters (location and magnitude). B\&W uses a grid search procedure to find the location which best fits the intensity observations. Boxer computes the barycenter (center of mass) of the spatial distribution of the sites experiencing the largest intensities by calculating an average of the geographical coordinates of such sites. MEEP approach is hybrid using first the MEEP centroid (equivalent to the Boxer barycenter) and then grid searching the region near it. All three methods assume a point source with no assumption regarding depth in Boxer. $\mathrm{B} \& \mathrm{~W}$ fixes depth of source to $10 \mathrm{~km}$ while MEEP includes depth determination based on the Kovesligethy (1906) model but in general for ill-behaved data sets values obtained should be regarded as unreliable (Musson, 2009).

The performance of each of the methods depends critically on the characteristics of the intensity field. The barycenter approach in Boxer is less biased by incorrect intensity assignments (either locations or values) but will fail if there are no reliable intensity assignments in the epicentral area. The same applies to MEEP in the determination of the MEEP centroid. B\&W approach is very sensitive to the density of intensity assignments, their spatial distribution, and the inconsistencies among the intensity values. In these cases, B\&W tends to locate the intensity center away from the observations. This effect is clearly observed when applying B\&W approach to the intensity assignments of the November 11, 1905 earthquake for which the intensity center (minimum $r m s\left[\mathrm{M}_{\mathrm{i}}\right]$ ) is located to the southwest away from the observations.

In all three methods, the macroseismic magnitude estimates depend on the regional intensity attenuation relation as derived based on a calibration set of earthquakes. This calibration set should include as many as possible earthquakes with moderate instrumental magnitudes, and at the same time, enough reliable intensity assignments covering the regional paths as densely as possible. Among the few earthquakes with moderate instrumental magnitudes in the region delimited by $117 \mathrm{~W}$ to $110 \mathrm{~W}$, and $40 \mathrm{~N}$ to $45 \mathrm{~N}$, those with reliable intensity assignments for at least three levels of intensity values and at least 60 intensity assignments greater or equal than IV were selected. The constraint of at least 60 values of intensity IV and greater assignments tries to minimize possible biases related to lower levels of intensity for which greater uncertainties in the assignments are likely to be expected (usually the low intensity fields of historical earthquakes are not well sampled in the archival accounts). Using the intensity assignments of the final set of seven calibration earthquakes the attenuation relations have been derived for Boxer and MEEP by running the calibration procedures. The more events that can be used for calibration, the better, but this is usually difficult for regions of moderate seismicity. The improvement of the attenuation relations can only be achieved when more calibration data are available which should vary in magnitude as much as possible.

The attenuation model for $\mathrm{B} \& \mathrm{~W}$ approach is adopted from the literature and is that of the Basin and Range province which is appropriate for earthquakes in the Utah-Idaho border region (Bakun, 2006).

The magnitude and location estimates obtained by using the intensity assignments of the calibration events and the either obtained or adopted attenuation relations for all methods are consistent with the instrumental location and magnitude values in the project catalog (see 
sections 4.3 and 4.4). Differences of few or a couple of tenths of $\mathrm{km}$ between the macroseismic and the instrumental catalog epicenter is to be expected because of different causes. First and most important, macroseismic epicentral location using intensity observations tries to estimate the location of the center of strong shaking while the instrumental epicenter represents the point at the surface where the earthquake rupture begins. The inherent uncertainty in instrumental locations together with the spatial distribution and consistency of the intensity observations in relation to the specific approach in a particular method contribute as well to the observed differences.

The two very recent events in 2020, the $E[M]=5.57$ March 18 Magna, UT, and the $E[M]=6.45$ March 31 Stanley, ID, together with the $E[M]=5.97$ February 21, 2008 Wells, NV, event have been incorporated in the analysis as independent validation events and not in the calibration set. The intensity assignments for these recent events are obtained by rounding Community Decimal Intensities (CDI) from the U.S. Geological Survey DYFI archives. Hough $(2013,2014)$ finds discrepancies between the attenuation of intensities estimated from traditional archival sources relative to DYFI although both document macroseismic effects of earthquakes. Intensity assignments from historical sources might bias intensity values because archival accounts tend to emphasize the most dramatic effects. To avoid as much as possible this kind of discrepancies in the derivation of the attenuation relations, the calibration set has just included events with traditional intensity observations while the most recent events with DYFI observations were used in the validation of the procedures.

The location and magnitude estimates obtained using the equivalent MMI (see section 4.4) for the three validation events suggest that the attenuation relations obtained are appropriate for earthquakes in the region. The differences observed between the macroseismic estimated location and magnitude and those instrumentally calculated in the catalog can be accounted for not only by the factors mentioned above for the calibration events but also from applying the attenuation relations as developed using traditional MMI intensity data to MMI equivalent intensity observations. The absolute differences between the macroseismic magnitudes and the instrumental magnitudes are less than 0.15 units in all cases except for the MEEP magnitude of the March 18, 2020 Magna, UT, which is 0.33 units larger.

In the analysis of historical earthquakes such as the November 11, 1905, for which the available intensity assignments are few with incomplete and spatially biased intensity fields, the methods based on grid searching (B\&W and MEEP) might perform best by using subsets of intensity assignments, which are apparently more complete. Using only levels IV and V assignments of two events (the $E[M]=5.72$ August 30, 1962 Cache Valley, UT, and the $E[M]=6.01$ March 28, 1975 Pocatello, ID) with unbiased intensity data in the application of $B \& W$ and MEEP methods it is shown that the estimates of magnitude vary within the expected uncertainty., The macroseismic estimates of B\&W and MEEP of the November 11, 1905 have been thus obtained using the more complete subsets IV and $V$ of the intensity assignments.

The macroseismic location and magnitude of the November 11, 1905 earthquake have been directly obtained from Boxer and MEEP approaches, while for B\&W approach a preferred location of the epicenter has been chosen. There is consistency in the location and magnitude as obtained by the three methods. The overlapping region of the $68 \%$ bootstrap resampling solutions for Boxer and MEEP suggests a reliable epicenter location within 41.550N $-42.060 \mathrm{~N}$ and 113.478W $-112.320 \mathrm{~W}$. This region encloses the original Oaks(1992) epicenter location and the MEEP centroid. The estimated Boxer and MEEP macroseismic magnitudes of 5.87 
and 6.00 respectively are consistent and these are in good agreement with B\&W estimated macroseismic magnitude of 6.05 at the preferred location. 


\section{REFERENCES}

Aleqabi GI, Wysession, ME (2006) QLg Distribution in the Basin and Range Province of the Western United States. Bull Seismol Soc Am 96, 348-354

Bakun WH (1999) Seismic activity of the San Francisco Bay region. Bull. Seismol. Soc. Am. 89, 764-784.

Bakun WH (2006) MMI Attenuation and Historical Earthquakes in the Basin and Range Province of Western North America. Bull. Seismol. Soc. Am. 96, 2206-2220.

Bakun WH, Wentworth CM (1997) Estimating earthquake location and magnitude from seismic intensity data. Bull. Seismol. Soc. Am. 87, 1502-1521

Bakun WH, Wentworth CM (1999) Erratum to Estimating earthquake location and magnitude from seismic intensity data. Bull. Seism. Soc. Am. 89, 557.

Bakun WH, Scotti O (2006) Regional intensity attenuation models for France and the estimation of magnitude and location of historical earthquakes, Geophys. J. Int. 164, 596-610.

Bakun WH, Haugerud RA, Hopper MG, Ludwin RS (2002) The December 1872 Washington State Earthquake, Bull. Seism. Soc. Am. 92, 3239-3258.

Bakun WH, Gómez-Capera A, Stucchi M (2011) Epistemic Uncertainty in the Location and Magnitude of Earthquakes in Italy from Macroseismic Data. Bull. Seismol. Soc. Am. 101, 27122725.

Cecić I, Musson RMW (2004) Macroseismic Surveys in Theory and Practice. Natural Hazards 31, 39-61.

Dengler LA, Dewey JW (1998) An Intensity Survey of Households Affected by the Northridge, California, Earthquake of 17 January, 1994. Bull Seismol Soc Am 88, 441-462

dePolo CM, Pecoraro M (2011) An Introduction to the February 21, 2008, Mw 6.0 Wells Nevada Earthquake and the Earthquake Documentation Volume, Nevada Bureau of Mines and Geology Special Publication 36, p. 15-42.

Durand ED (1918) Thirteenth Census of the United States taken in the year 1910, Statistics for Idaho. Dept. of Commerce and Labor, Bureau of the Census, Washington, $89 \mathrm{pp}$. (https://www2.census.gov/library/publications/decennial/1910/abstract/supplement-id.pdf)

Eulenfeld T, Wegler U (2017) Crustal intrinsic and scattering attenuation of high-frequency shear waves in the contiguous United States. J. Geophys. Res. Solid Earth, 122, 4676-4690, doi:10.1002/2017JB014038.

Evans JP, Martindale DC, Kendrick RD Jr. (2003) Geologic Setting of the 1884 Bear Lake, Idaho, Earthquake: Rupture in the Hanging Wall of a Basin and Range Normal Fault Revealed by Historical and Geological Analyses, Bull. Seismol. Soc. Am. 93, 1621-1632.

Frankel A (1994) Implications of felt area-magnitude relations for earthquake scaling and the average frequency of perceptible ground motion. Bull. Seismol. Soc. Am., 84, 462-465. 
Gallegos A, Ranasinghe N, Ni J, Sandvol E (2017) Lg attenuation, frequency dependence and relative site response of the western United States as revealed by the EarthScope Transportable Array. Geophys. J. Int. 209, 1955-1971.

Gasperini P, Bernardini F, Valensise G, Boschi E (1999) Defining seismogenic sources from historical earthquake felt reports. Bull. Seismol. Soc. Am. 89:94-110.

Gasperini P, Vannucci G, Tripone D, and Boschi E (2010) The location and sizing of historical earthquakes using the attenuation of macroseismic intensity with distance, Bull. Seismol. Soc. Am. 100, 2035-2066.

Harpham LK (1991) Idaho earthquakes of 1905, 1913, and 1916: Intensity, location, and magnitude inferred from newspaper accounts. MS Thesis, Boise State University, 55 pp.

Hough S (2013). Spatial variability of "Did You Fell It?" Intensity data: insights into sampling biases in historical earthquake intensity distributions. Bull. Seismol. Soc., 103, 2767-278

Hough S (2014) Earthquake intensity distributions: a new view. Bull. Earthquake Eng., 12, 135155.

INL (1996) Site-Specific Probabilistic Seismic Hazard Analyses for the Idaho National Engineering Laboratory. Volume 1 Final Report, Volume 2 Appendices. INEL-95/053

INL (2016) SSHAC Level 1 Probabilistic Seismic Hazard Analysis for the Idaho National Laboratory. INL/EXT-15-36682, Revision 2, doi: 10.2172/1367865.

Kövesligethiy RD (1906) A makroszeizmikus rengesek feldolgozasa, Mathematikai es Termeszettudomanyi Ertesito 24, 349-368.

Moschetti MP, Ritzwoller MH, Lin F-C, Yang Y (2010) Crustal shear wave velocity structure of the western United States inferred from ambient seismic noise and earthquake data. J. Geophys. Res. 115, B10306. doi:10.1029/2010JB007448

Musson RMW (2009) MEEP 2.0 user guide, British Geological Survey Open Report OR/09/045, $22 \mathrm{pp}$.

Musson RMW, Jimenez MJ (2008) Macroseismic estimation of earthquake parameters, "NERIES project report", NA4, Deliverable D3 (Edinburgh), 41 pp.

Oaks SD (1992) Historical seismicity investigation for the November 11, 1905 earthquake; EG\&G Informal Report EGG GEO 10203, 106 p.

Pasolini C, Gasperini P, Albarello D, Lolli B, D'Amico V (2008) The attenuation of seismic intensity in Italy, Part I: Theoretical and empirical backgrounds, Bull. Seismol. Soc. Am. 89, 682-691.

Sibol MS, Bollinger GA, Birch JB (1987) Estimations of magnitudes in central and eastern North America using intensity and felt area, Bull. Seismol. Soc. Am. 77, 1635-1654.

Topozada TR (1975) Earthquake magnitude as a function of intensity data in California and Western Nevada. Bull. Seismol. Soc. Am. 65 (5), 1223-1238. 
Townley SD, Allen MW (1939) Descriptive Catalog of Earthquakes of the Pacific Coast of the United States 1769 to 1928. Bull. Seismol. Soc. Am. 29 (1), 1-297.

USNRC (2012) NUREG-2115 Central and Eastern United States Seismic Source Characterization for Nuclear Facilities. Washington, D.C.: U.S. Nuclear Regulatory Commission.

Wells D.L., Coppersmith K.J. (1994) New empirical relationships among magnitude, rupture length, rupture width, rupture area, and surface displacement, Bull. Seismol. Soc. Am. 84, 974-1002. 


\section{Appendix A}

\section{BOXER \& MEEP TECHNIQUES \\ (CALIBRATION EVENTS)}





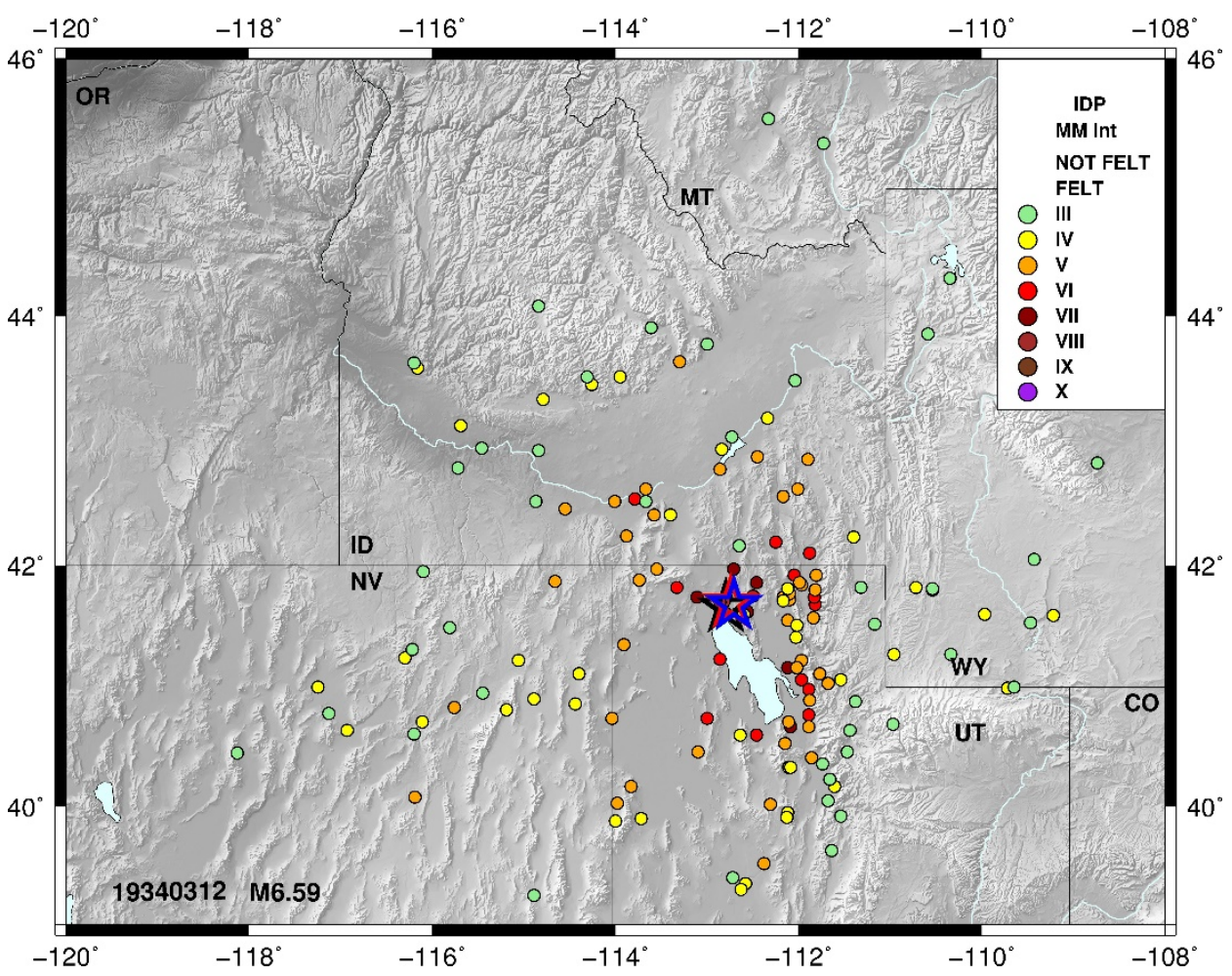

Figure A1. Event 1934/03/12 Hansel Valley, UT. Colored circles are intensity assignments. Star colors for epicenter locations are as follows: INL_SL3 catalog- black; Boxer -red; MEEP - blue. Inset: MMI intensity color code. $M$ in bottom legend is $E[M]$.

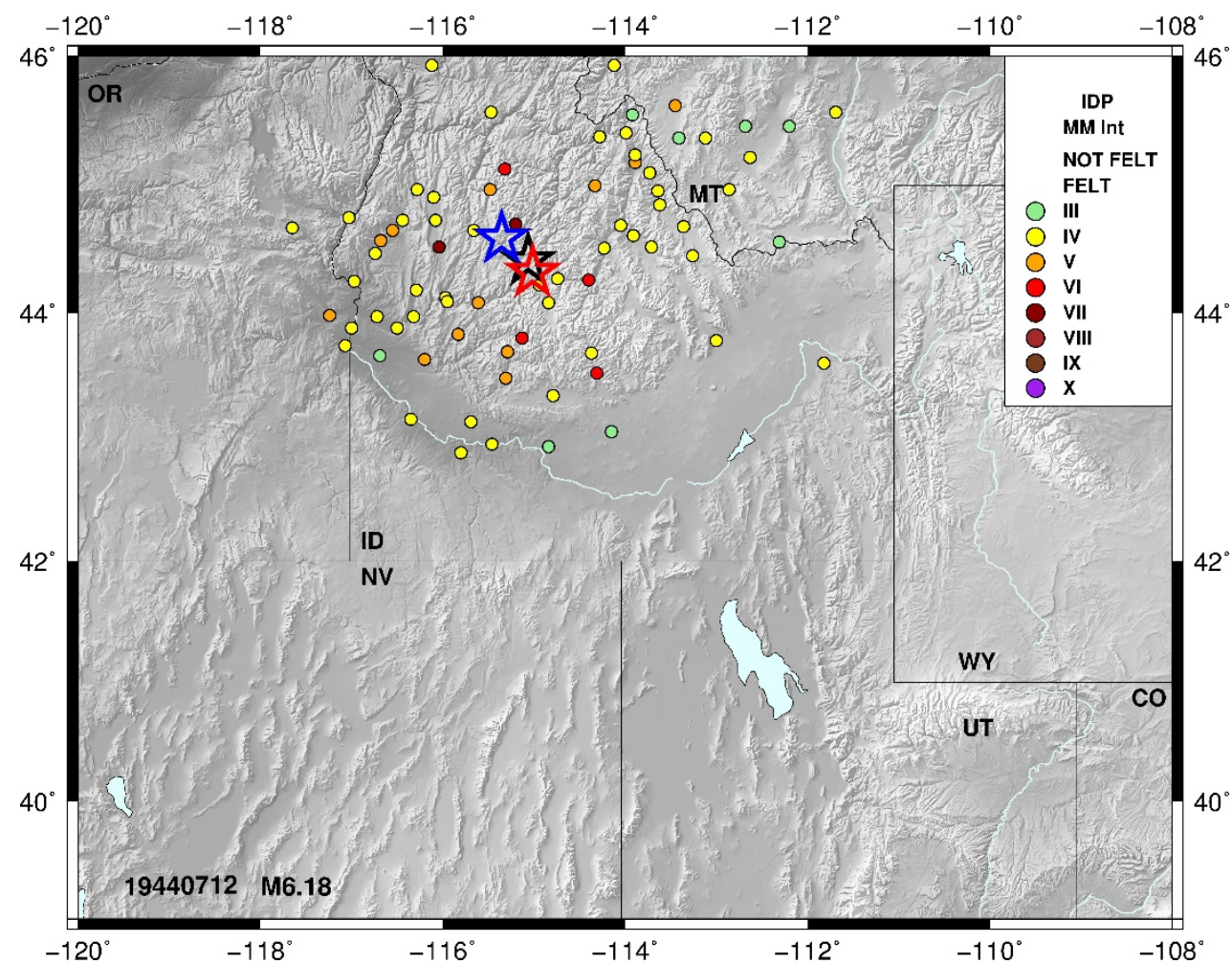

Figure A.2. Event 1944/07/12 S. Idaho. Colored circles are intensity assignments. Star colors for epicenter locations are as follows: INL_SL3 catalog -black; Boxer -red; MEEP - blue. Inset: MMI intensity color code. $M$ in bottom legend is $E[M]$. 


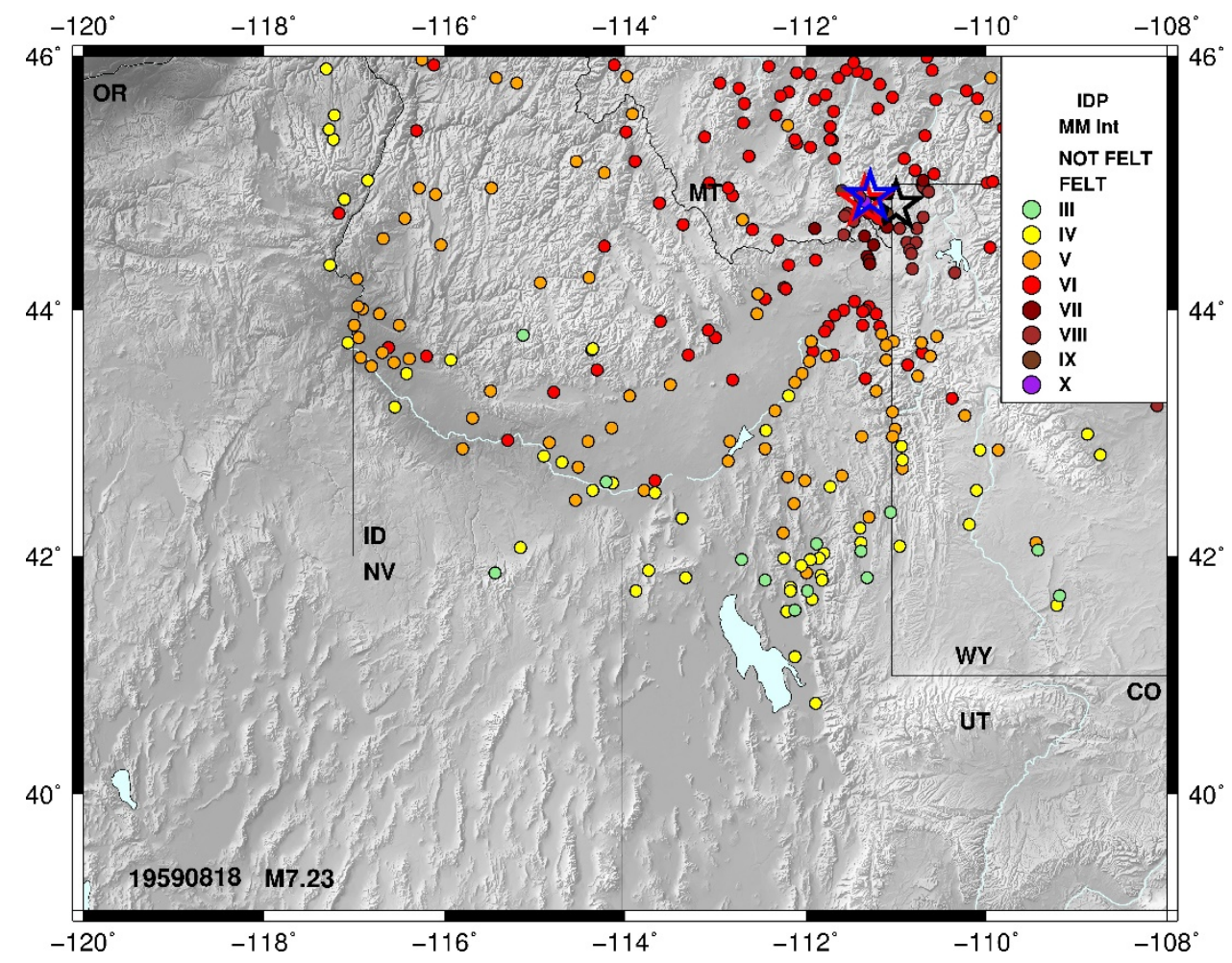

Figure A.3. Event 1959/08/18 Hebgen Lake, MT. Colored circles are intensity assignments. Star colors for epicenter locations are as follows: INL_SL3 catalog -black; Boxer -red; MEEP - blue. Inset: MMI intensity color code. M in bottom legend is E[M].

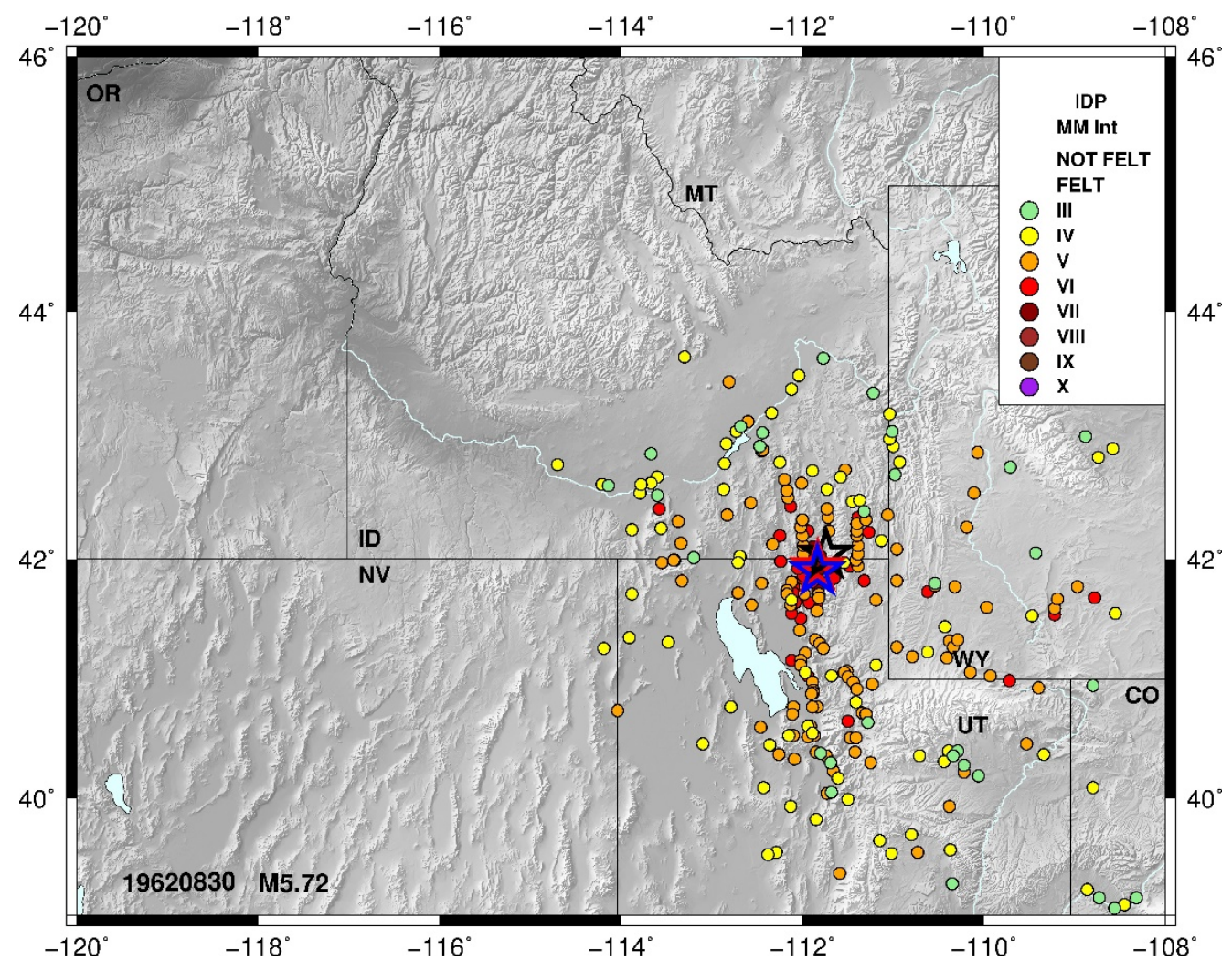

Figure A.4. Event 1962/08/30 Cache Valley, UT. Colored circles are intensity assignments. Star colors for epicenter locations are as follows: INL_SL3 catalog - black; Boxer -red; MEEP - blue. Inset: MMI intensity color code. $M$ in bottom legend is $E[M]$. 


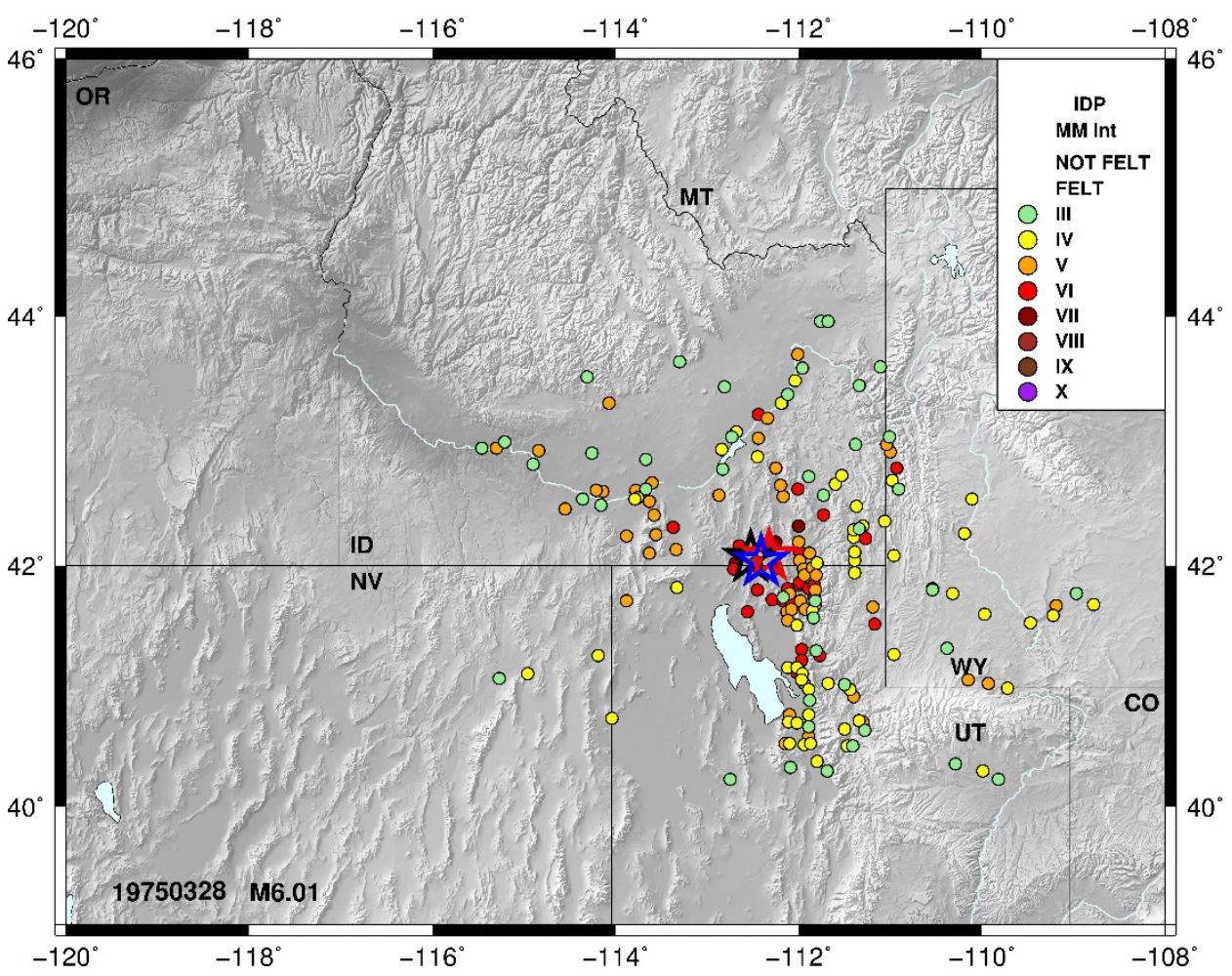

Figure A.5. Event 1975/03/28 Pocatello, ID. Colored circles are intensity assignments. Star colors for epicenter locations are as follows: INL_SL3 catalog - black; Boxer -red; MEEP blue. Inset: MMI intensity color code. M in bottom legend is E[M].

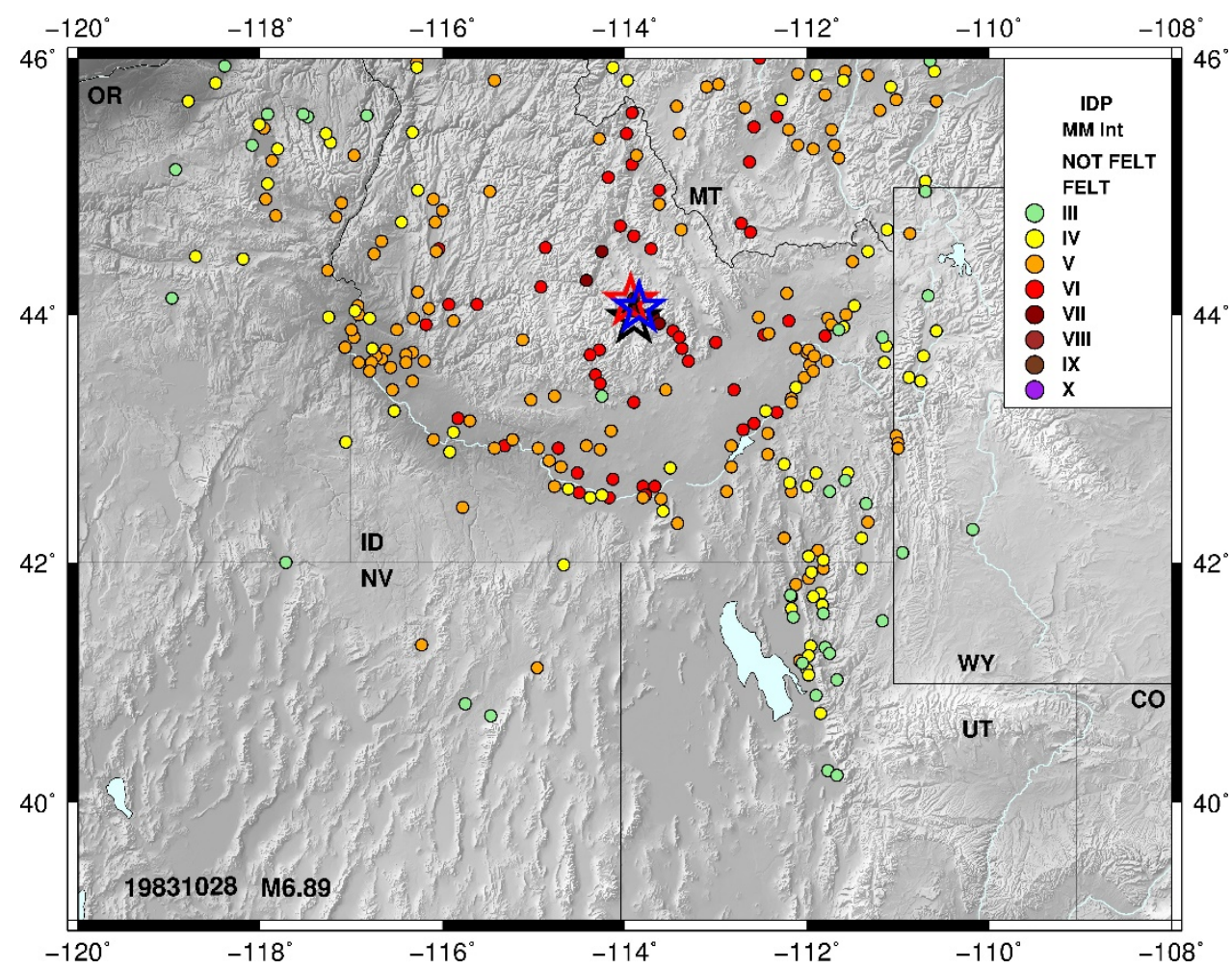

Figure A.6. Event 1983/10/28 Borah Peak, ID. Colored circles are intensity assignments. Star colors for epicenter locations are as follows: INL_SL3 catalog - black; Boxer -red; MEEP - blue. Inset: MMI: intensity color code. $M$ in bottom legend is E[M]. 


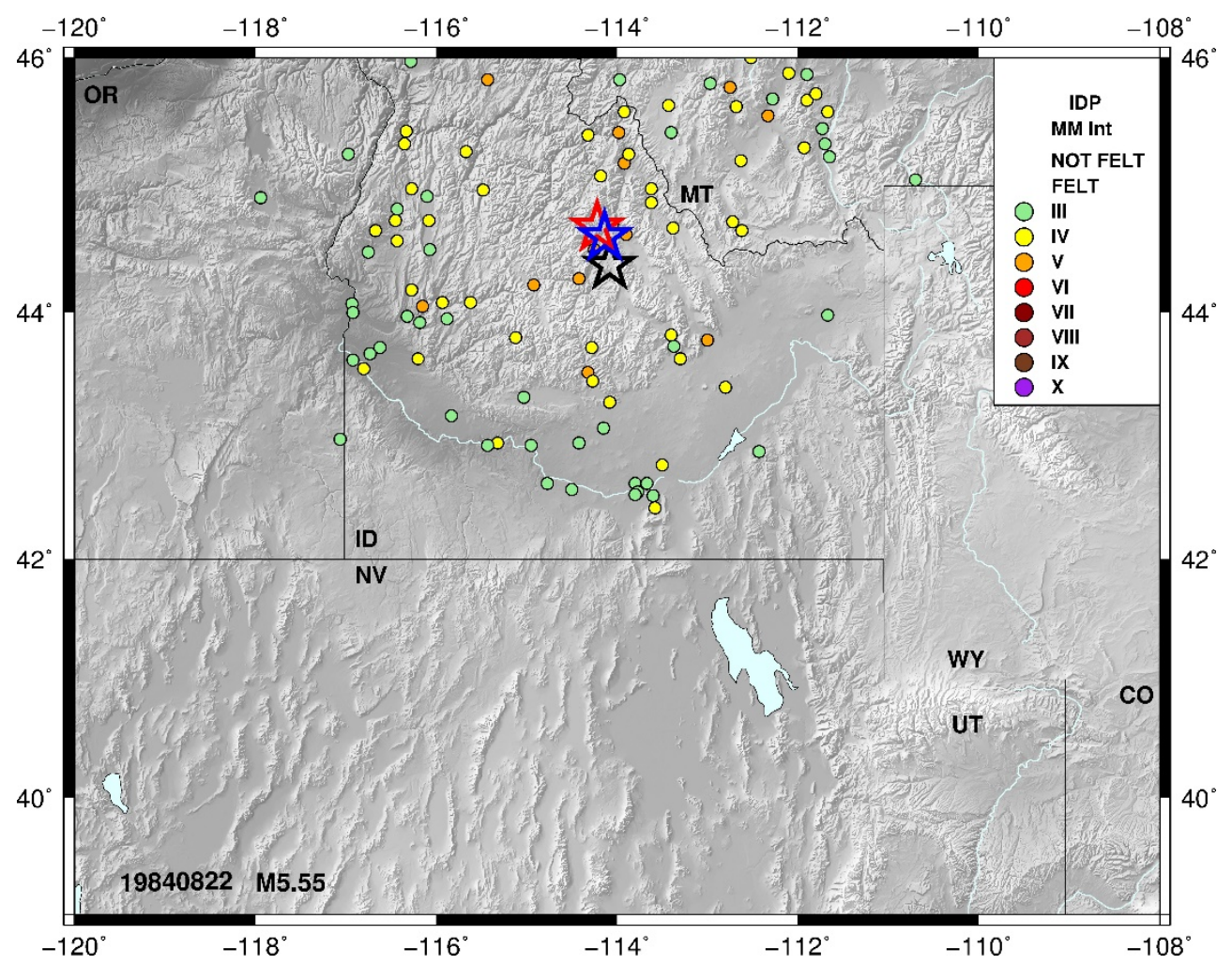

Figure A.7. Event 1984/08/22 S. Idaho. Colored circles are intensity assignments. Star colors for epicenter locations are as follows: INL_SL3 catalog - black; Boxer -red; MEEP - blue. Inset: MMI intensity color code. $M$ in bottom legend is $E[M]$. 


\section{Appendix B}

\section{BOXER, B\&W \& MEEP TECHNIQUES \\ (VALIDATION EVENTS)}





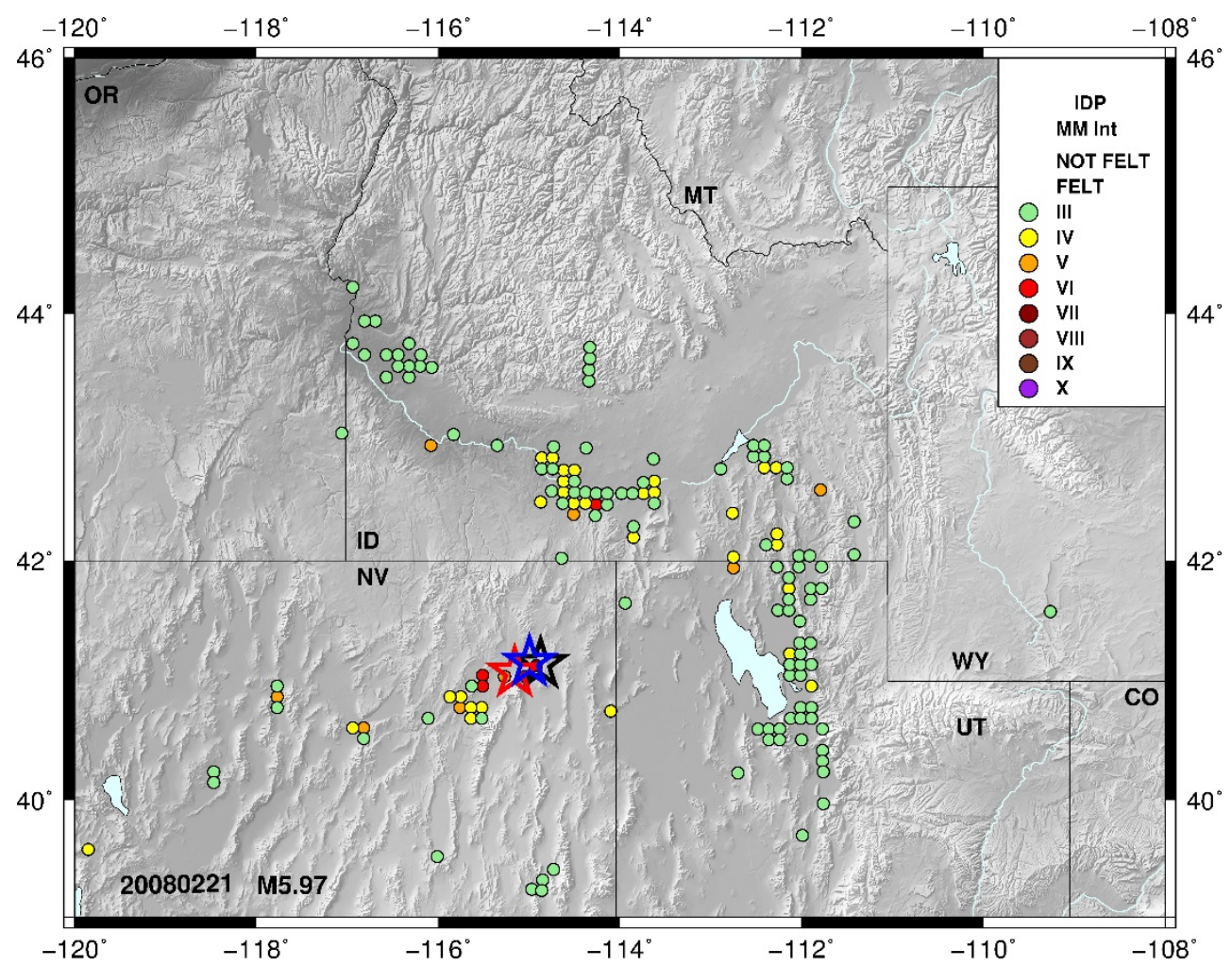

Figure B.1. Event 2008/02/21 Wells, NV. Colored circles are intensity assignments. Star colors for epicenter locations are as follows: INL_SL3 catalog - black; Boxer -red; MEEP blue. Inset: $M M I$ intensity color code. $M$ in bottom legend is $E[M]$.

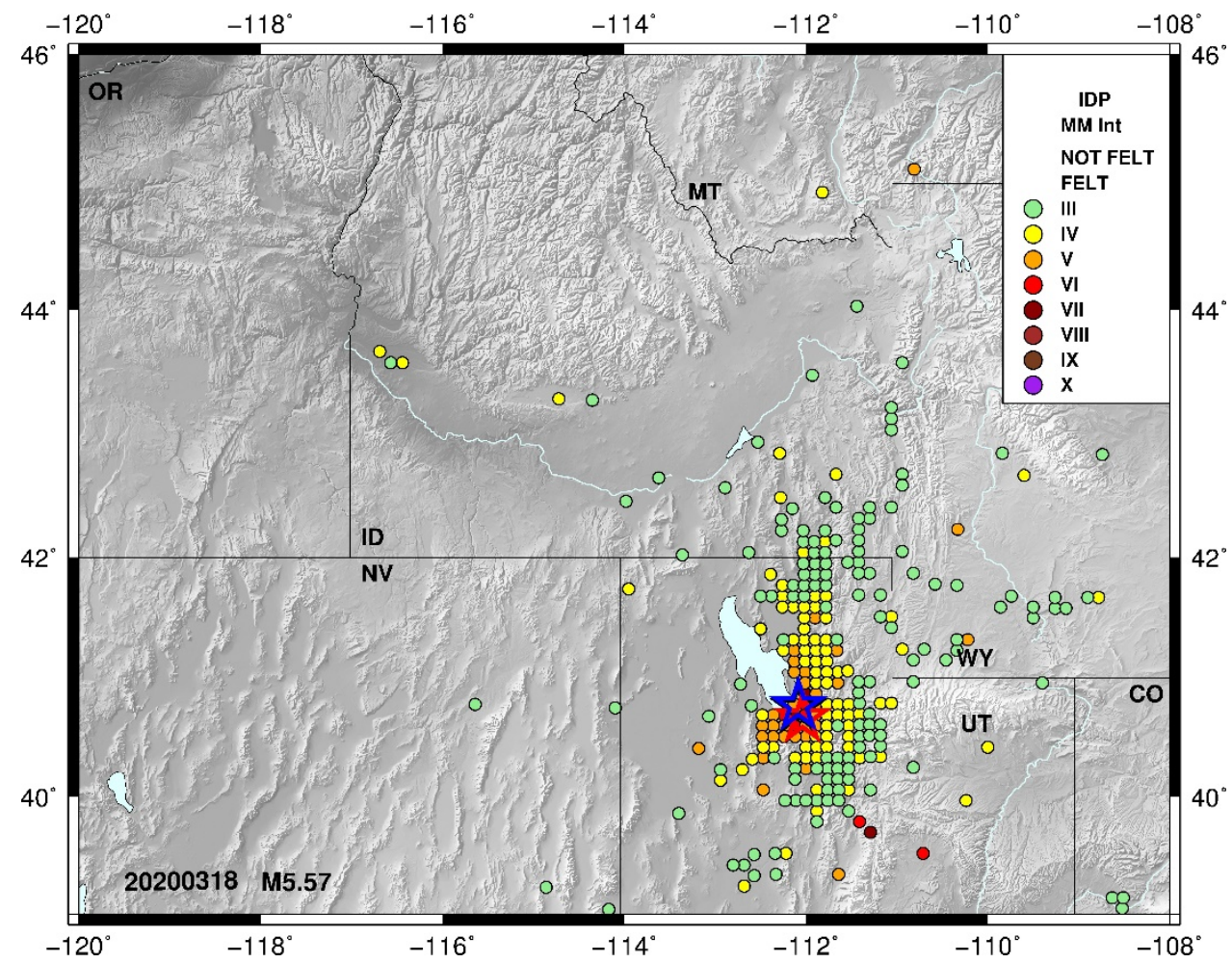

Figure B.2. Event 2020/03/18 Magna, UT. Colored circles are intensity assignments. Star colors for epicenter locations are as follows: INL_SL3 catalog - black; Boxer -red; MEEP blue. MEEP and INL_SL3 catalog epicenters overlap (less than $2 \mathrm{~km}$ away) Inset: MMI intensity color code. $M$ in bottom legend is E[M]. 


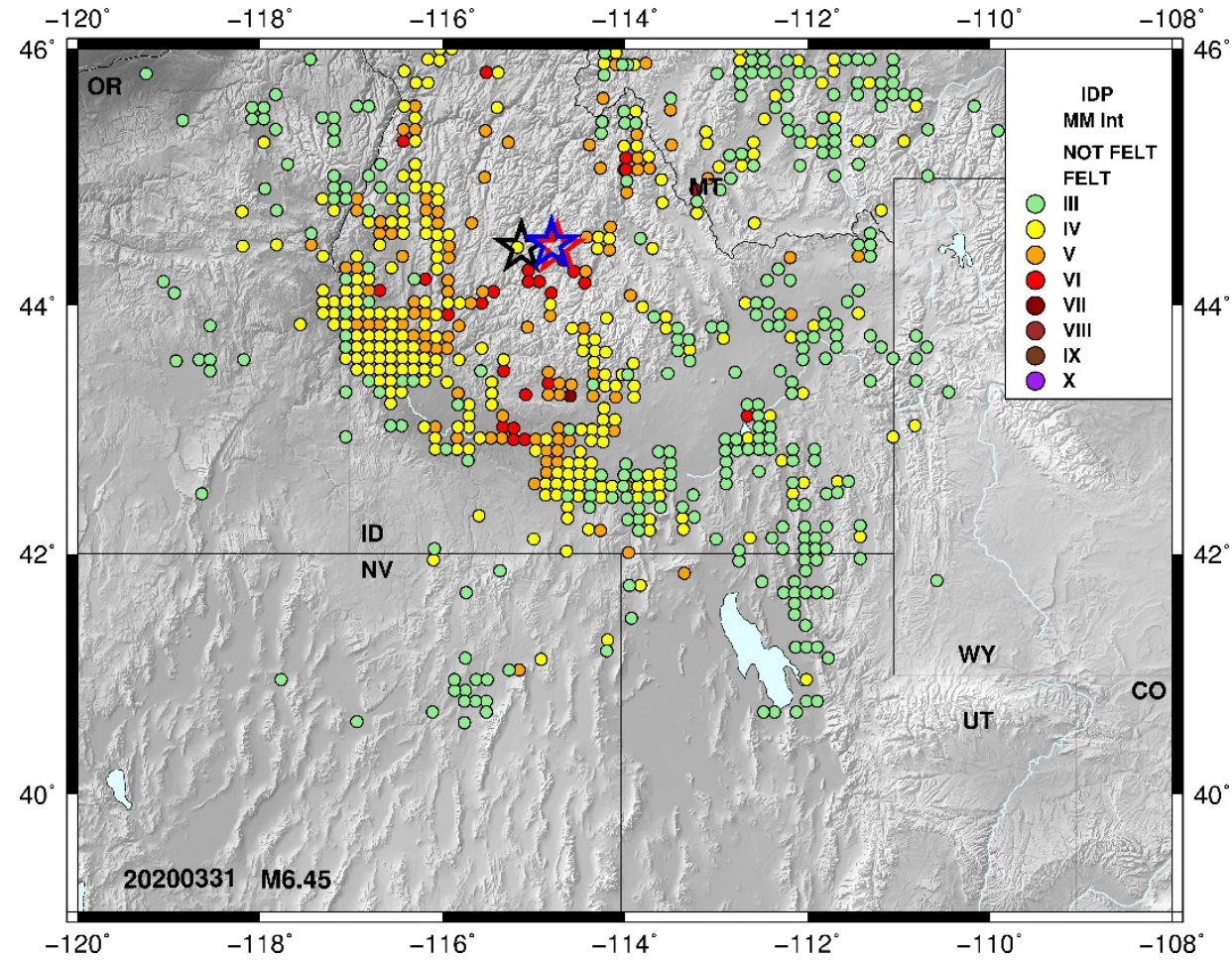

Figure B.3. Event 2020/03/31 Stanley, ID. Colored circles are intensity assignments. Star colors for epicenter locations are as follows: INL_SL3 catalog - black; Boxer -red; MEEP blue. Inset: MMI intensity color code. $M$ in bottom legend is E[M]. 


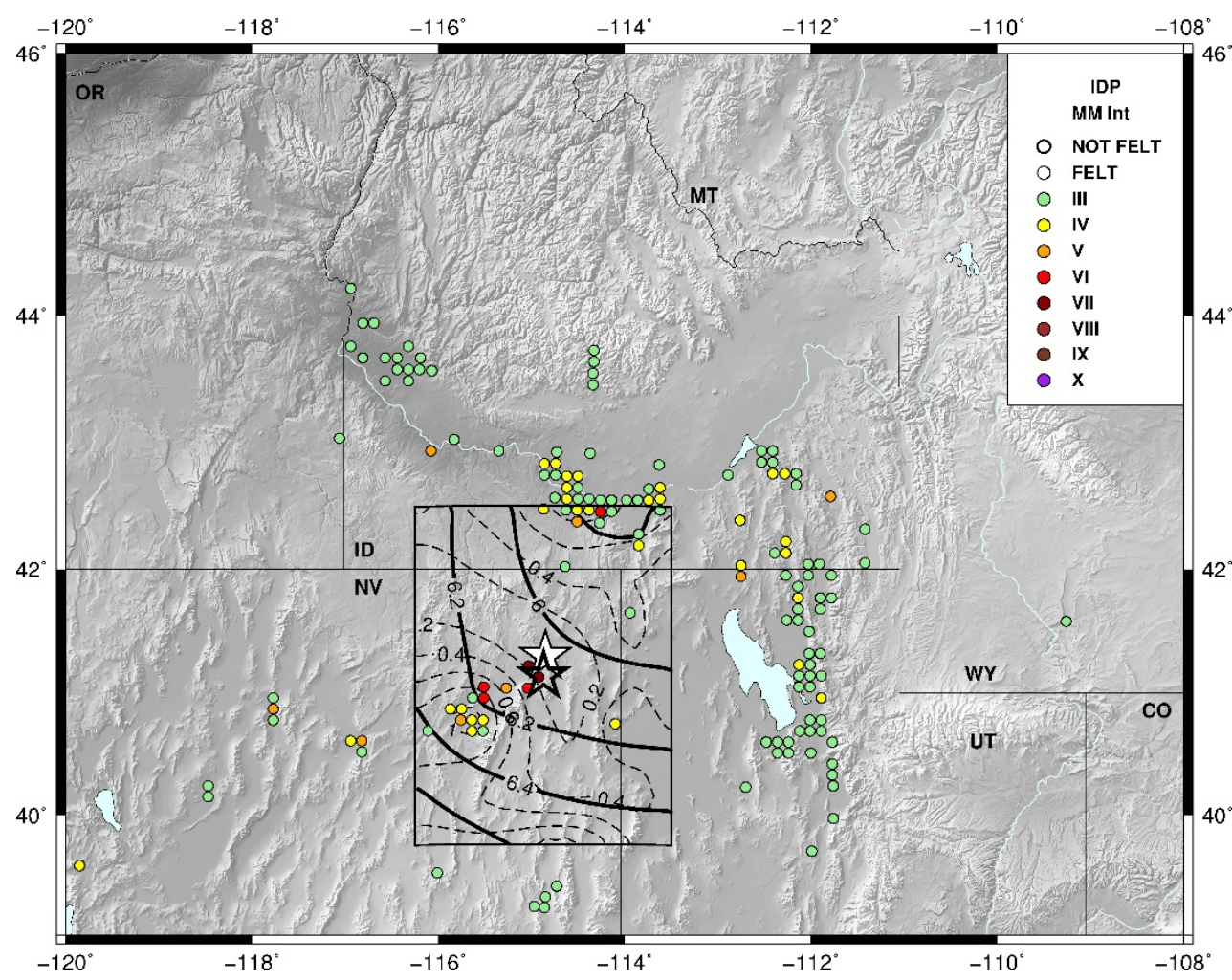

Figure B.4. Event 2008/02/21 Wells, NV. Colored circles are intensity assignments. Star colors for epicenter locations are as follows: INL_SL3 catalog - black; B\&W - white. Inset: MMI intensity color code.

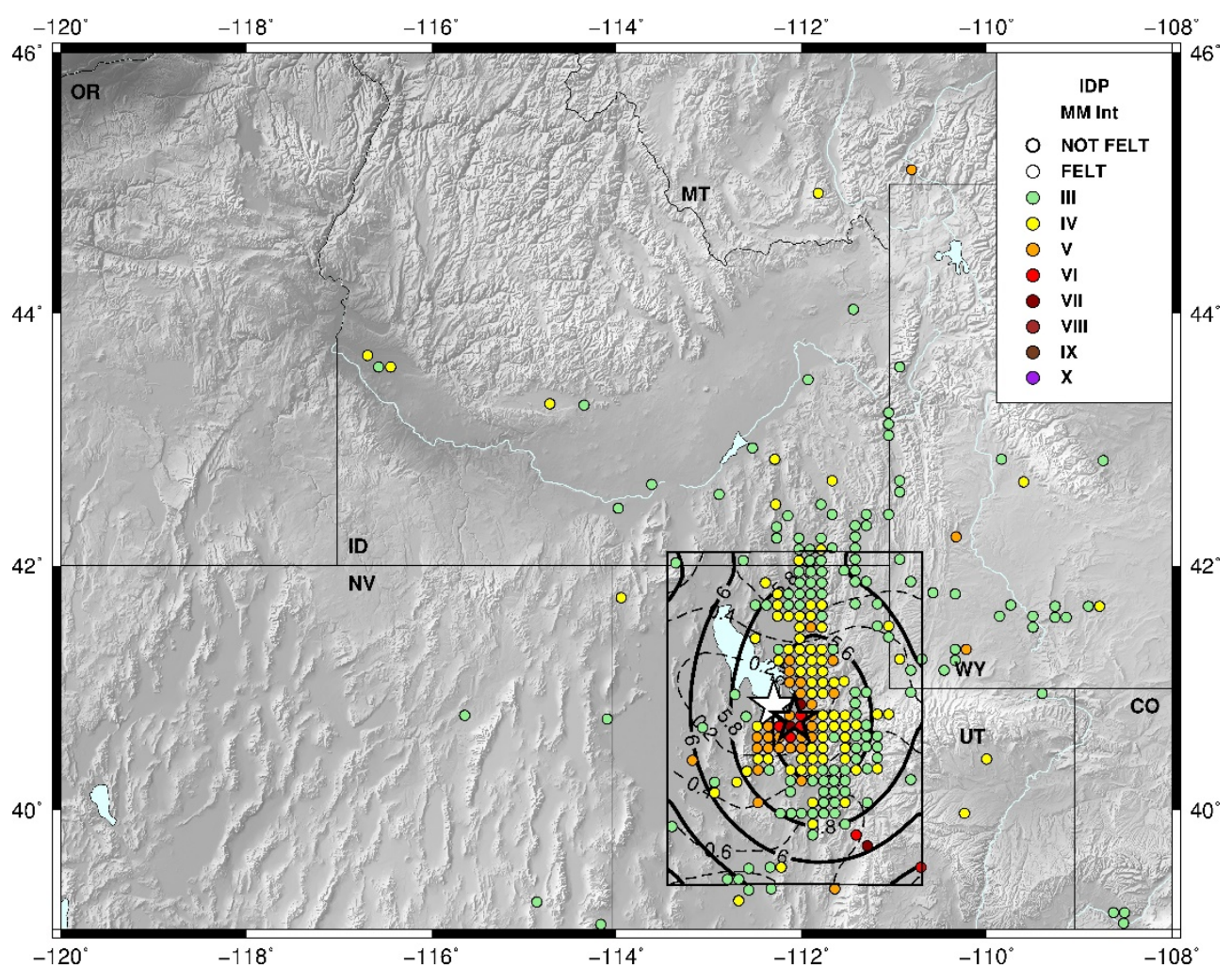

Figure B.5. Event 2020/03/18 Magna, UT. Colored circles are intensity assignments. Star colors for epicenter locations are as follows: INL_SL3 catalog - black; B\&W - white. Inset: MMI intensity color code. 


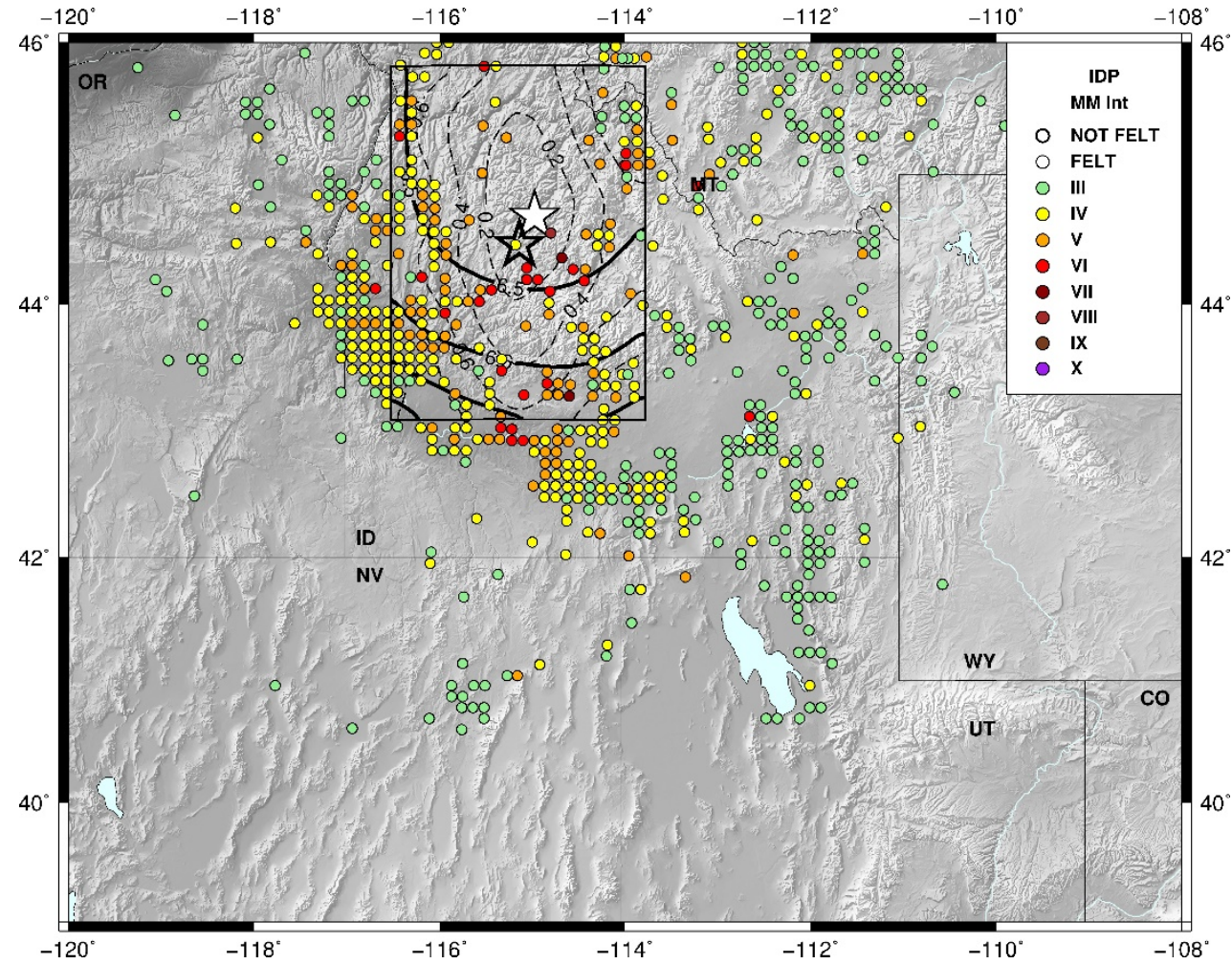

Figure B.6. Event 2020/03/31 Stanley, ID. Colored circles are intensity assignments. Star colors for epicenter locations are as follows: INL_SL3 catalog - black; B\&W - white. Inset: MMI intensity color code. 